Article

\title{
Analysis of the Additional Stress and Ground Settlement Induced by the Construction of Double-O-Tube Shield Tunnels in Sandy Soils
}

\author{
Wen Zhao ${ }^{1}$, Peng-jiao Jia ${ }^{1, * \mathbb{C}}$, Lin Zhu ${ }^{2}$, Cheng Cheng ${ }^{1}$, Jianyong Han ${ }^{1,3}$, Yang Chen ${ }^{1, * \mathbb{D}}$ and \\ Zhi-guo Wang ${ }^{1}$ \\ 1 School of Resources \& Civil Engineering, Northeastern University, Shenyang 110819, China; \\ wenneu@163.com (W.Z.); chengchengneu@163.com (C.C.); hanlwb@163.com (J.H.); \\ wzhiguo1995@163.com (Z.-g.W.) \\ 2 Liaoning Transportation Science Research Institute Co., Ltd., Shenyang 110015, China; 13840079972@163.com \\ 3 School of Civil Engineering of Shandong Jianzhu University, Jinan 250014, China \\ * Correspondence: jpengjiao@163.com (P.-j.J.); chenyangyang.net@163.com (Y.C.); \\ Tel.: +86-182-0243-7531 (P.-j.J.); +86-155-0248-6481 (Y.C.)
}

Received: 25 January 2019; Accepted: 26 March 2019; Published: 3 April 2019

check for updates

\begin{abstract}
Double-O-tube shield tunneling has attracted increasing attention because it offers cost-efficiency in underground construction. Prediction of ground surface settlement and the variety of additional stresses induced by shield construction is crucial to underground construction in metropolises since excessive settlement could trigger potential damage to the surrounding environment. The additional stresses induced by the propulsion of double-O-tube shields are calculated by means of the Mindlin's equations of elasticity. The characteristics of additional stresses are analyzed with compound Gauss-Legendre integral arithmetic, and the frontal additional thrust, the lateral friction, and the ground loss are taken into account. Subsequently, based on field measurements, the maximum settlement coefficient and width of the settlement trough coefficient of the typical Peck formula are modified. The predictive curve of the Peck formula is closer to the engineering measured data than that of the typical formula. The cut-off functions of ground surface settlement caused by double-O-tube tunnel shield construction are proposed and can predict the shape of ground surface settlement, such as single peak or double peak. The correctness of the proposed functions is verified based on an engineering project.
\end{abstract}

Keywords: shield tunnel; Mindlin's solution; additional stress; Peck formula; ground surface settlement

\section{Introduction}

With the rapid development of urban construction, a series of problems has been caused because of heavy transportation systems and a lack of public space in the metropolises [1,2]. Currently, metro transportation has become the main way to solve traffic congestion. It can effectively reduce the heavy transportation problem, but it also adversely affects the surrounding environments, such as ground surface settlement and stress redistribution of soil [3-5].

The ground surface settlement induced by tunnel construction has been widely investigated, and estimation of the settlement trough has been a key factor in related studies [6-12]. Meanwhile, several analytical methods have been adopted to predict ground surface settlement caused by the tunnel excavation [13,14]. On one hand, it is very important to understand the mechanics of the development of stress and deformation by applying analytical approaches. On the other hand, these are generally complicated and inconvenient to directly evaluate the settlement. In engineering projects, empirical 
formulas have been widely adopted to estimate ground surface settlement, especially some simple expressions. The Peck formula [15] is one of the most widely used empirical equations according to field measurements. To improve the practicality of the formula to general cases, the formula was modified and developed in other studies [16-20].

According to above references, most studies are devoted to ground surface settlement caused by single-line tunnels in clay and soft layer, and few investigations have focused on double-O-tube tunnels in a sand layer. Compared to single-line tunnels, there are more factors that induce ground surface settlement, such as interactions between left and right tunnels, especially urban tunnels, which usually have a larger size. Therefore, the predication formula of the ground surface settlement caused by double-O-tube tunnels in a sand layer is investigated in this paper.

Due to the limitations of geological conditions and construction technology, and although shield construction technology has made great progress in recent years, it inevitably disturbs the soil and causes ground surface settlement or uplift, which has been investigated by some scholars [21-26]. There are few analyses of the additional stresses in surrounding soil caused by construction. Previous studies generally only consider the effect of frontal additional thrust and friction between the shield shell and the soil on additional stress [24,27-30]. The influence of ground loss on additional loads is not considered in the sand stratum. Additionally, most soil layers of the additional stresses during shield construction are located in the clay soil and lack some studies on sandy soil. Moreover, for the current studies of Mindlin's solution, frontal additional thrust of tunnel is usually defined as $20 \mathrm{kPa}$. Friction between the shield shell and the soil is assumed as uniform distribution along a radial direction of the shield. The vertical pressure of the center of the tunnel is defined as the mean pressure. For the aforementioned studies, it is a lager gap with the actual condition. Finally, few investigations have focused on the cut-off function predicted shape of the surface settlement curve.

In this research, theoretical calculations of the additional stress caused by shield construction, the modified Peck formula, and the shape of the ground surface settlement curve are studied based on data from line 4 of the Xian metro under construction by two tunnel boring machines (TBMs).

The five main research topics are as follows: (1) to give the calculation of frontal additional thrust and friction between the shield shell and the soil; (2) based on Mindlin's solution of elasticity, frontal additional thrust and friction between the shield shell and the soil and ground loss are considered to investigate the stress distribution characteristics of the soil around double-O-tube shield tunneling after excavation; (3) the Peck formula is modified to better predict the ground surface settlement compared with the typical Peck formula for a sand layer; (4) the settlement pattern of the tunnel, the influence of the burial depth and the spacing, and the soil parameters on the surface settlement curve are studied based on three-dimensional finite element models; (5) the cut-off function's predicted shape of the surface settlement curve, such as single and double peaks, is proposed.

\section{Project Overview}

The project studied in this work is located in Xian, which is the biggest city in north-western China. The selected sections of this project are located in the Wen-Feng tunneling interval of Xi'an metro line 4. The entire length of $\mathrm{Xi}^{\prime}$ an metro line 4 is $35.2 \mathrm{~km}$. The Wen-Feng tunneling interval consists of two parallel shield tunnels, which are known as the left and right lines, constructed using an EPB (earth pressure balanced) shield. The buried depth of the two parallel shield tunnels is $15.2 \mathrm{~m}$. The outer diameter of the constructed tunnel is $6 \mathrm{~m}$ with a lining thickness of $0.3 \mathrm{~m}$.

To clearly understand the ground settlement of the shield tunnel for typical geologies of $\mathrm{Xi}^{\prime}$ an, the monitoring results from three sections $(\mathrm{K} 28+744, \mathrm{~K} 28+773, \mathrm{~K} 28+803)$ were selected for analysis. Detailed positions of the shield tunnels and soil layers are shown in Figure 1, and mechanical properties of the different soil layers are shown in Table 1. 


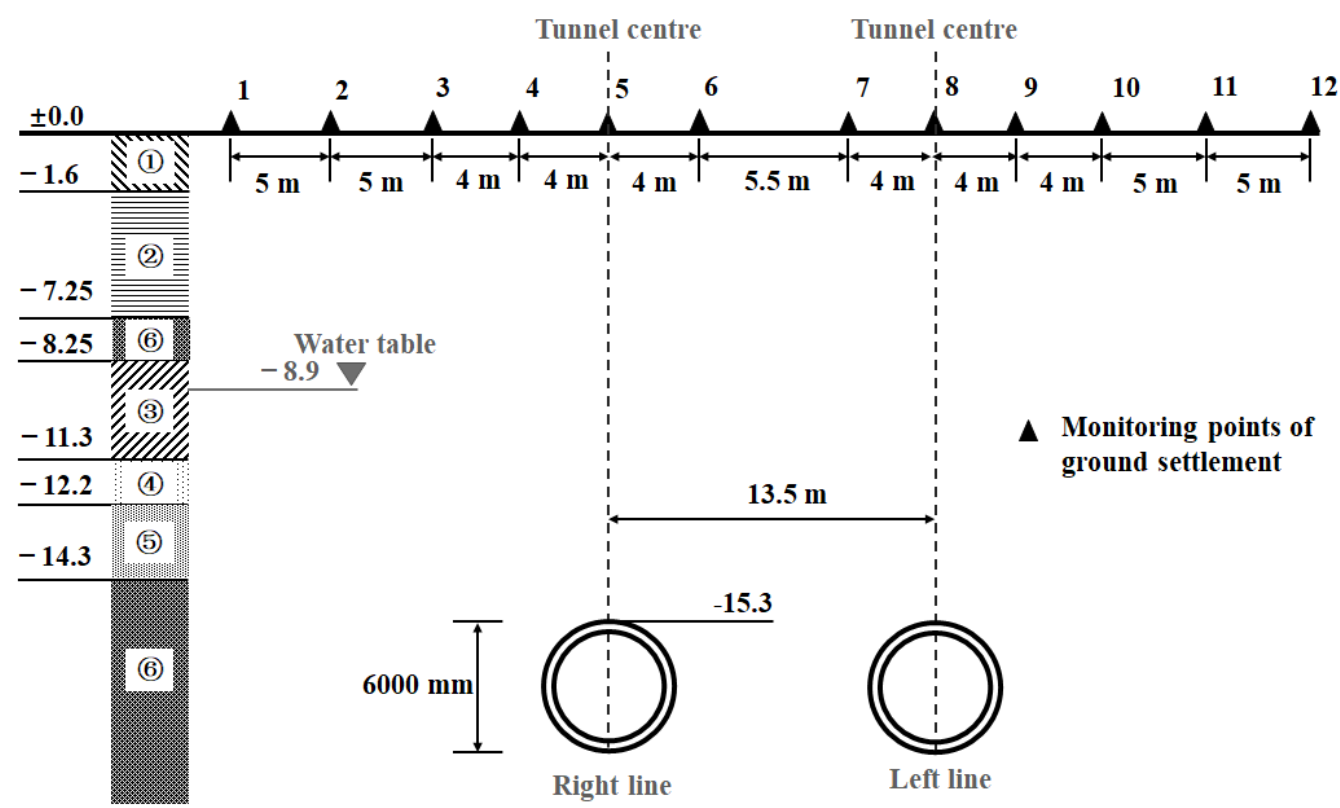

Figure 1. Cross-section view of the shield tunnels and different soil layers.

Table 1. Mechanical properties of the different soil layers.

\begin{tabular}{ccccccc}
\hline $\begin{array}{c}\text { Number of } \\
\text { Soil Layers }\end{array}$ & Soil Type & $\begin{array}{c}\gamma_{\text {sat }} \\
\mathbf{( k N / \mathbf { m } ^ { 3 }} \mathbf{)}\end{array}$ & $\begin{array}{c}\gamma \\
\mathbf{( k N / \mathbf { m } ^ { 3 }}\end{array}$ & $\left.\boldsymbol{\phi} \mathbf{(}^{\circ}\right)$ & $\boldsymbol{c}(\mathbf{k p a})$ & $\mathbf{I}_{\mathbf{L}}$ \\
\hline (1) & Backfill soil & - & 17.3 & 15 & 10 & 0.18 \\
(2) & Loess soil & - & 19.1 & 26 & 36 & 0.28 \\
(3) & Silty clay & 20.3 & 19.9 & 24.5 & 38 & 0.52 \\
(4) & Silty-fine sand & 21 & 18.8 & 28.6 & 4.8 & - \\
(5) & Medium sand & 21.2 & 19.5 & 31.8 & 7.0 & - \\
(6) & Coarse sand & 21.4 & 20.8 & 34.2 & 7.1 & - \\
\hline
\end{tabular}

Note: $\gamma_{\text {sat }}$ is the saturated unit weight, $\gamma$ is the natural unit weight, $\phi$ is the internal friction angle, $c$ is the cohesion, and $I_{\mathrm{L}}$ is the liquid index.

\section{Theoretical Calculation of the Additional Stress Caused by Shield Construction}

\subsection{Mechanical Models and Assumptions}

During shield propulsion, the stress field of the surrounding soil is affected by the frontal additional thrust, friction between the shield shell and the surrounding soil, and the ground loss. A mechanical model of shield propulsion is shown in Figure 2. In 1936, based on the Galerkin's displacement function, Mindlin [31] derived the stress and deformation formula of any point in a semi-infinite spatial body acting on a concentrated force, as shown in Figure 3. Assuming that soil is an isotropic elastic semi-infinite body, Mindlin solved the additional stress at any point $(x, y, z)$ of the surrounding soil for a horizontal concentrated force $\mathrm{P}$ acting at a distance $\mathrm{c}$ from the surface. 


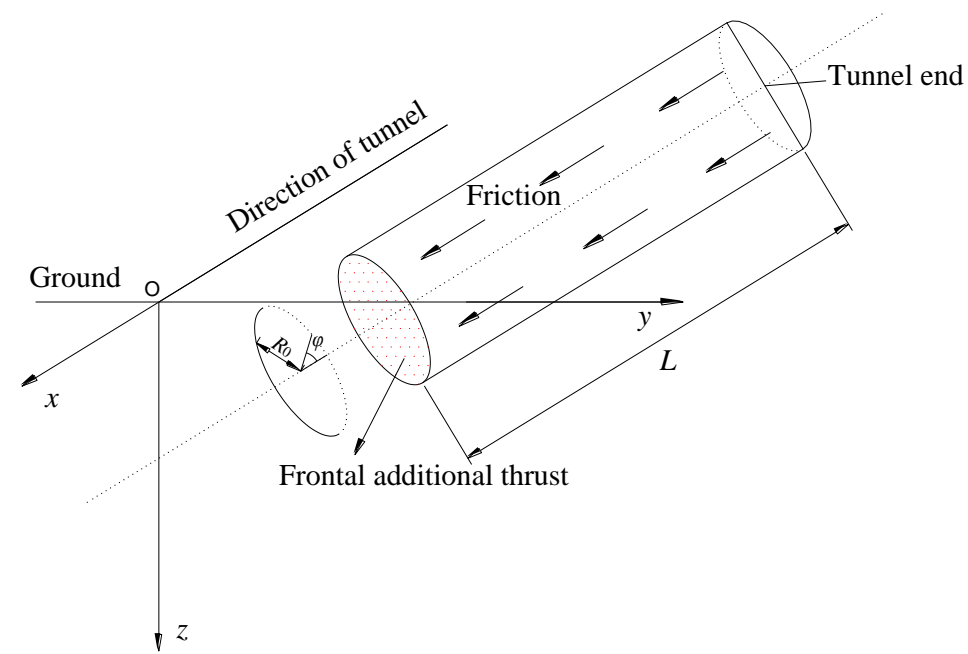

Figure 2. Mechanical model of the shield tunneling construction.

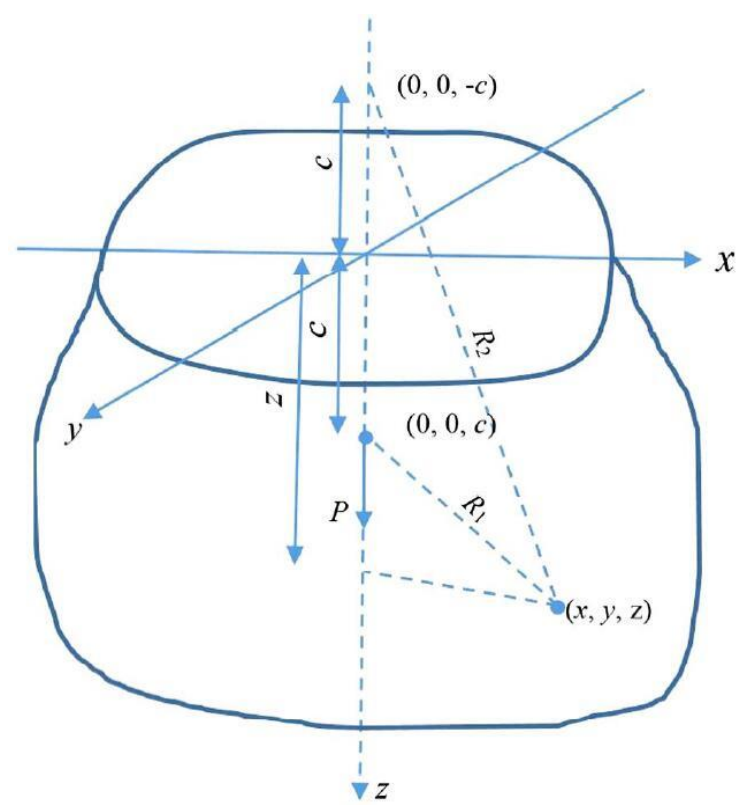

Figure 3. Mindlin's solution for a horizontal force [32].

\subsection{Theoretical Calculation Method}

\subsubsection{Frontal Additional Thrust Due to the Friction between the Shield and the Soil}

From Figures 2 and 3, the load degree of the thrust of the differential element is $p$, and the load of the differential element is $p \mathrm{~d} r \mathrm{~d} \theta$. Based on Mindlin's solution, an additional stress at any point $(x, y, z)$ in the soil is obtained by calculating the integral of the uniform load in the circular region as follows:

$$
\begin{aligned}
& \sigma_{x 1}=\int_{0}^{2 \pi} \int_{0}^{\frac{D}{2}} \frac{P x}{8 \pi(1-\mu)}\left\{\frac{(1-2 \mu)}{R_{1}{ }^{3}}-\frac{(1-2 \mu)(5-4 \mu)}{R_{2}{ }^{3}}+\frac{3 x^{2}}{R_{1}{ }^{5}}+\frac{3(3-4 \mu) x^{2}}{R_{2}{ }^{5}}\right. \\
& +\frac{4(1-\mu)(1-2 \mu)}{R_{2}\left(R_{2}+z+c-r \sin \theta\right)^{2}}\left[3-\frac{x^{2}\left(3 R_{2}+z+c-r \sin \theta\right)}{R_{2}{ }^{2}\left(R_{2}+z+c-r \sin \theta\right)}\right] \\
& -\frac{6(c-r \sin \theta)}{R_{2}{ }^{5}}\left[3(c-r \sin \theta)-(3-2 \mu)(z+c-r \sin \theta)+\frac{5 x^{2} z}{R_{2}{ }^{2}}\right] r \mathrm{~d} r \mathrm{~d} \theta
\end{aligned}
$$




$$
\begin{aligned}
& \sigma_{y 1}=\int_{0}^{2 \pi} \int_{0}^{\frac{D}{2}} \frac{P x}{8 \pi(1-\mu)}\left\{\frac{(1-2 \mu)}{R_{1}{ }^{3}}-\frac{(1-2 \mu)(5-4 \mu)}{R_{2}{ }^{3}}+\frac{3 y^{2}}{R_{1}{ }^{5}}+\frac{3(3-4 \mu) y^{2}}{R_{2}{ }^{5}}\right. \\
& +\frac{4(1-\mu)(1-2 \mu)}{R_{2}\left(R_{2}+z+c-r \sin \theta\right)^{2}}\left[3-\frac{(y+r \cos \theta)^{2}\left(3 R_{2}+z+c-r \sin \theta\right)}{R_{2}{ }^{2}\left(R_{2}+z+c-r \sin \theta\right)}\right] \\
& \left.-\frac{6(c-r \sin \theta)}{R_{2}{ }^{5}}\left[c-r \sin -(1-2 \mu)(z+c-r \sin \theta)+\frac{5(y-r \cos \theta)^{2} z}{R_{2}{ }^{2}}\right]\right\} r \mathrm{~d} r \mathrm{~d} \theta
\end{aligned}
$$

where $R$ is the radius of the shield tunneling machine, and $P$ is horizontal force $(\mathrm{kN}), c$ is the distance of from action point of horizontal force to ground surface, $\mu$ is the Poisson ratio, $R_{1}$ and $R_{2}$ are the distance of the action spot and symmetry point to stress point $(x, y, z), \theta$ represents the angle from the horizontal plane, and $z$ is the distance of stress point to ground surface.

\subsubsection{Additional Stress Due to the Friction between the Shield and the Soil}

In polar coordinates, the differential element $R \mathrm{~d} l \mathrm{~d} \theta$ of the shield machine surface is taken and integrated by the elastic Mindlin's solution so that the additional stress at any point $(x, y, z)$ is as follows:

$$
\begin{aligned}
& \sigma_{x 2}=\int_{0}^{2 \pi} \int_{0}^{L} \frac{P(x+l)}{8 \pi(1-\mu)}\left\{\frac{(1-2 \mu)}{R_{1}{ }^{3}}-\frac{(1-2 \mu)(5-4 \mu)}{R_{2}{ }^{3}}+\frac{3(x+l)^{2}}{R_{1}{ }^{5}}+\frac{3(3-4 \mu)(x+l)^{2}}{R_{2}{ }^{5}}\right. \\
& +\frac{4(1-\mu)(1-2 \mu)}{R_{2}\left(R_{2}+z+c-r \sin \theta\right)^{2}}\left[3-\frac{(x+l)^{2}\left(3 R_{2}+z+c-r \sin \theta\right)}{R_{2}{ }^{2}\left(R_{2}+z+c-r \sin \theta\right)}\right] \\
& \left.-\frac{6(c-r \sin \theta)}{R_{2}{ }^{5}}\left[3(c-R \sin \theta)-(3-2 \mu)(z+c-R \sin \theta)+\frac{5(x+l)^{2} z}{R_{2}{ }^{2}}\right]\right\} R \mathrm{~d} l \mathrm{~d} \theta \\
& \sigma_{y 2}=\int_{0}^{2 \pi} \int_{0}^{L} \frac{P(x+l)}{8 \pi(1-\mu)}\left\{\frac{(1-2 \mu)}{R_{1}{ }^{3}}-\frac{(1-2 \mu)(5-4 \mu)}{R_{2}{ }^{3}}+\frac{3(y+R \cos \theta)^{2}}{R_{1}{ }^{5}}+\frac{3(3-4 \mu)(y+R \cos \theta)^{2}}{R_{2}{ }^{5}}\right. \\
& +\frac{4(1-\mu)(1-2 \mu)}{R_{2}\left(R_{2}+z+c-R \sin \theta\right)^{2}}\left[1-\frac{(y+R \cos \theta)^{2}\left(3 R_{2}+z+c-R \sin \theta\right)}{R_{2}{ }^{2}\left(R_{2}+z+c-r \sin \theta\right)}\right] \\
& \left.-\frac{6(c-R \sin \theta)}{R_{2}{ }^{5}}\left[c-R \sin \theta-(1-2 \mu)(z+c-R \sin \theta)+\frac{5(y-r \cos \theta)^{2} z}{R_{2}{ }^{2}}\right]\right\} R \mathrm{~d} l \mathrm{~d} \theta
\end{aligned}
$$

where $l$ is the length of the shield tunneling machine.

\subsubsection{Additional Stress Caused by Shield Ground Loss}

Sagaseta [33] proposed a "source-sink method" to calculate the variety of stress fields caused by ground loss in linear elastic semi-infinite bodies. The displacement component generated by an area with a radius a the point $\left(x_{0}, y_{0}, z_{0}\right)$ is Equation (5) at the point $(x, y, z)$, and the displacement component generated by mirror image is defined in Equation (6) as follows:

$$
\begin{aligned}
& \left\{\begin{array}{l}
S_{x 1}=-\frac{a^{3}\left(x-x_{0}\right)}{3 r_{1}{ }^{3}} \\
S_{y 1}=-\frac{a^{3}\left(y-y_{0}\right)}{3 r_{1}{ }^{3}}
\end{array},\right. \\
& \left\{\begin{array}{l}
S_{x 1}=-\frac{a^{3}\left(x-x_{0}\right)}{3 r_{2}{ }^{3}} \\
S_{y 1}=-\frac{a^{3}\left(y-y_{0}\right)}{3 r_{2}{ }^{3}}
\end{array}\right.
\end{aligned}
$$

where $r_{1}=\left[\left(x-x_{0}\right)^{2}+\left(y-y_{0}\right)^{2}+\left(z-z_{0}\right)^{2}\right]^{1 / 2} r_{2}=\left[\left(x-x_{0}\right)^{2}+\left(y-y_{0}\right)^{2}+\left(z+z_{0}\right)^{2}\right]^{1 / 2}, a$ is radius of void at the point $\left(x_{0}, y_{0}, z_{0}\right)$, and $S_{x 1}, S_{x 1}, S_{x_{3}}$, and $S_{x_{4}}$ are components of displacement.

Combined with the basic equation for elastic mechanics, the stress generated by these two steps can be calculated by Equation (7) as follows:

$$
\left\{\begin{array}{c}
\sigma_{x}=\frac{E \mu}{(1+\mu)(1-2 \mu)}\left(\varepsilon_{x}+\varepsilon_{y}+\varepsilon_{z}\right)+2 G \varepsilon_{x} \\
\sigma_{y}=\frac{E \mu}{(1+\mu)(1-2 \mu)}\left(\varepsilon_{x}+\varepsilon_{y}+\varepsilon_{z}\right)+2 G \varepsilon_{y}
\end{array},\right.
$$

where $E$ is the elastic modulus, $\mu$ is the Poisson ratio, and $G$ is the shear modulus of the soil. 
By substituting Equations (5)-(7) into Mindlin's solution, the additional stress calculation Equations (8)-(9) generated by steps 1 and 2 are obtained. From this, the shear stress $\tau_{x z}$ and $\tau_{y z}$ induced by the previous two steps at the surface may counteract on the ground. Based on Cerruti's solution, the stress calculation Equations (10)-(11) for the third step are proposed as follows:

$$
\begin{aligned}
& \sigma_{x 3-1}=a^{3} \frac{E}{3(1-2 \mu)}\left(\frac{1}{r_{2}{ }^{3}}-\frac{1}{r_{1}{ }^{3}}\right)+a^{3} \frac{E(1-\mu)}{3(1+\mu)(1-2 \mu)}\left(x-x_{0}\right)^{2}\left(\frac{1}{r_{1}{ }^{5}}-\frac{1}{r_{2}{ }^{5}}\right)+a^{3} \frac{\mu E}{(1+\mu)(1-2 \mu)} \\
& \times\left[\left(y-y_{0}\right)^{2}\left(\frac{1}{r_{1}^{5}}-\frac{1}{r_{2}{ }^{5}}\right)+\left(z-z_{0}\right)^{2} \frac{1}{r_{1}^{5}}-\left(z+z_{0}\right)^{2} \frac{1}{r_{2}{ }^{5}}\right] \text {, } \\
& \sigma_{y 3-1}=a^{3} \frac{E}{3(1-2 \mu)}\left(\frac{1}{r_{2}{ }^{3}}-\frac{1}{r_{1}{ }^{3}}\right)+a^{3} \frac{E(1-\mu)}{3(1+\mu)(1-2 \mu)}\left(y-y_{0}\right)^{2}\left(\frac{1}{r_{1}{ }^{5}}-\frac{1}{r_{2}{ }^{5}}\right)+a^{3} \frac{\mu E}{(1+\mu)(1-2 \mu)} \\
& \times\left[\left(x-x_{0}\right)^{2}\left(\frac{1}{r_{1}^{5}}-\frac{1}{r_{2}^{5}}\right)+\left(z-z_{0}\right)^{2} \frac{1}{r_{1}^{5}}-\left(z+z_{0}\right)^{2} \frac{1}{r_{2}{ }^{5}}\right] \text {, } \\
& \sigma_{x 3-2}=\frac{a^{3}}{\pi} \frac{E}{1+\mu} \lim _{b \rightarrow \infty} \lim _{b \rightarrow \infty} \int_{y_{0}-b}^{y_{0}+b} \int_{x_{0}-d}^{x_{0}+d} \frac{z_{0}(x-u)\left(u-x_{0}\right)}{\left[\left(u-x_{0}\right)^{2}+\left(t-y_{0}\right)^{2}+z_{0}{ }^{2}\right]^{\frac{5}{2}}}\left\{\frac{1-2 \mu}{(\mathrm{W}+z)^{2}}\left[\frac{1}{W}+\frac{(y-t)^{2}}{W^{3}}-\frac{2(y-t)^{2}}{W^{2}(W+z)}\right]-\frac{3(x-u)^{2}}{W^{5}}\right\} \mathrm{d} u \mathrm{~d} t+ \\
& \frac{a^{3}}{\pi} \frac{E}{1+\mu} \lim _{b \rightarrow \infty d \rightarrow \infty} \lim _{y_{0}-b}^{y_{0}+b} \int_{x_{0}-d}^{x_{0}+d} \frac{z_{0}(y-t)\left(t-y_{0}\right)}{\left[\left(u-x_{0}\right)^{2}+\left(t-y_{0}\right)^{2}+z_{0}^{2}\right]^{\frac{5}{2}}}\left\{\frac{1-2 \mu}{(W+z)^{2}}\left[\frac{1}{W}-\frac{(x-u)^{2}}{W^{3}}-\frac{2(x-u)^{2}}{W^{2}(W+z)}\right]-\frac{3(y-t)^{2}}{W^{5}}\right\} \mathrm{d} u \mathrm{~d} t, \\
& \sigma_{y 3-2}=\frac{a^{3}}{\pi} \frac{E}{1+\mu} \lim _{b \rightarrow \infty} \lim _{b \rightarrow \infty} \int_{y_{0}-b}^{y_{0}+b} \int_{x_{0}-d}^{x_{0}+d} \frac{z_{0}(x-u)\left(u-x_{0}\right)}{\left[\left(u-x_{0}\right)^{2}+\left(t-y_{0}\right)^{2}+z_{0}{ }^{2}\right]^{\frac{5}{2}}}\left\{\frac{1-2 \mu}{(\mathrm{R}+\mathrm{z})^{2}}\left[\frac{3}{R}+\frac{(x-u)^{2}}{R^{3}}-\frac{2(x-u)^{2}}{W^{2}(W+z)}\right]-\frac{3(y-t)^{2}}{W^{5}}\right\} \mathrm{d} u \mathrm{~d} t+ \\
& \frac{a^{3}}{\pi} \frac{E}{1+\mu} \lim _{b \rightarrow \infty d \rightarrow \infty} \int_{y_{0}-b}^{y_{0}+b} \int_{x_{0}-d}^{x_{0}+d} \frac{z_{0}(y-t)\left(t-y_{0}\right)}{\left[\left(u-x_{0}\right)^{2}+\left(t-y_{0}\right)^{2}+z_{0}^{2}\right]^{\frac{5}{2}}}\left\{\frac{1-2 \mu}{(\mathrm{R}+\mathrm{z})^{2}}\left[\frac{3}{W}-\frac{(y-t)^{2}}{W^{3}}-\frac{2(y-)^{2}}{W^{2}(W+z)}\right]-\frac{3(x-u)^{2}}{W^{5}}\right\} \mathrm{d} u \mathrm{~d} t .
\end{aligned}
$$

In a semi-infinite body, the total additional stress generated by an area with a radius a a point $\left(x_{0}, y_{0}, z_{0}\right)$ is Equation (12) at the point $(x, y, z)$ as follows:

$$
\left\{\begin{array}{l}
\sigma_{x 3}=\sigma_{x 3-1}+\sigma_{x 3-2} \\
\sigma_{y 3}=\sigma_{y 3-1}+\sigma_{y 3-2}
\end{array},\right.
$$

The additional stress generated by a unit void volume is as follows:

$$
\left\{\begin{array}{l}
\sigma_{x 3^{\prime}}=\frac{3 \sigma_{x 3}}{4 \pi a^{3}} \\
\sigma_{y 3^{\prime}}{ }^{\prime}=\frac{3 \sigma_{y 3}}{4 \pi a^{3}}
\end{array},\right.
$$

The stress is generally integrated by the stress solution generated by the unit volume gap during the process of shield propulsion. When soil is excavated along the positive direction of the $x$-axis, the additional stress caused by the ground loss can be calculated by Equation (14) as follows:

$$
\sigma_{i}=\iiint_{V_{1}-V_{2}} \sigma_{i}^{\prime}(x, y, z) \mathrm{d} x \mathrm{~d} y \mathrm{~d} z ; i=x, y
$$

\subsubsection{Equation for Calculating the Additional Stress under Joint Action}

Under the joint action mentioned above, the additional stress generated at any point $(x, y, z)$ of the surrounding soil is superimposed to obtain the following Equation (15) set:

$$
\left\{\begin{array}{l}
\sigma_{x}=\sigma_{x 1}+\sigma_{x 2}+\sigma_{x 3} \\
\sigma_{y}=\sigma_{y 1}+\sigma_{y 2}+\sigma_{y 3}
\end{array}\right.
$$

\subsection{Case Study}

\subsubsection{The Value of Key Parameters}

1) The frontal additional thrust $\left(P_{1}\right)$

Based on the current studies on Mindlind's solution, the frontal additional thrust is usually defined as $20 \mathrm{kPa}$, but in reality, the value of field measurements reached 170 190 kPa. Thus, the 
compressive effect of cutterhead on soil is underestimated [27,28]. Wang and Chen [34,35] pointed out that the extrusion effect is divided into two parts-one part is produced by the roll of cutterhead, and the other is formed by extrusion force produced by cutting into the soil. The calculated formula is as follows:

$$
P_{1}=\frac{10.31(1-\mu) E_{u} \pi v(1-\xi)^{2}}{(1+\mu)(3-4 \mu) D k \omega}+\Delta p^{\prime},
$$

where $P_{1}$ is the frontal additional thrust, $\mu$ is the Poisson ratio, $E_{u}$ is the undrained elastic modulus, $v$ is the aperture opening ratio of cutterhead, $D$ is the diameter of cutterhead, $k$ is the amplitude number of closed part of cutterhead, $\omega$ is the rotational speed of cutterhead of the shield machine, and $\Delta p^{\prime}$ is the extrusion force produced by cutting into the soil.

2) The friction between the shield shell and the soil $\left(\mathrm{P}_{2}\right)$

For the current study results, the friction between the shield shell and the soil is assumed to be uniform distribution along the radial direction of the shield, and the vertical pressure of the center of the tunnel is defined as the mean pressure. There is a larger difference with the actual condition. Based on the research results of the friction of the pile-soil interface and considering the friction softening between the shield shell and the soil, the expression is as follows [27,28]:

$$
P_{2}=\eta \sigma_{\theta} \tan \theta,
$$

where $\eta$ is the softening coefficient, $\sigma_{\theta}$ is normal stress at the $\theta$ angle of the shield shell, and $\phi$ is the internal friction angle.

\subsubsection{Frontal Additional Thrust}

The distribution curve of the frontal additional stress $\sigma_{x}$ is shown in Figure 4 along the y direction, which is caused by the frontal stress in the center of the tunnel. The response of the additional stress field is the largest near the centerline of the tunnel, and the amplitude is also the largest, which is the main reason for the surface uplift in front of the shield. The farther the distance from the tunnel face is, the smaller the additional stress is. This results in slower attenuation to both sides of the tunnel from the centerline but a larger influence range. The maximum normal additional stress is $3.9 \mathrm{kPa}$ at a distance of $1 \mathrm{~m}$ from the tunnel face, and the stress decreases rapidly towards both sides. At a distance of $8 \mathrm{~m}$ from the tunnel face, the additional stress is nearly zero, and the influence range is mainly within approximately one tunnel diameter from the tunnel centerline. The calculation parameters are shown in Table 2, where $P_{1}$ is the frontal additional thrust, $f$ is the friction coefficient between the shield shell and the soil, $P_{2}$ is the friction between the shield shell and the soil, $\mu$ is the Poisson ratio, $H$ is the buried depth of the tunnel, and $R$ is the radius of the shield machine.

Table 2. Calculation parameters.

\begin{tabular}{cccccc}
\hline $\boldsymbol{P}_{\mathbf{1}} \mathbf{( \mathbf { P a } )}$ & $\boldsymbol{f}$ & $\boldsymbol{P}_{\mathbf{2}} \mathbf{( k P a )}$ & $\boldsymbol{\mu}$ & $\boldsymbol{H}(\mathbf{m})$ & $\boldsymbol{R}(\mathbf{m})$ \\
\hline 25 & 0.3 & 46.3 & 0.3 & 14 & 3.14 \\
\hline
\end{tabular}

The distribution curve of the lateral additional stress $\sigma_{y}$ distribution is shown in Figure 5 along the $y$ direction. The closer the distance from the tunnel face is, the greater the additional stress is. The lateral additional stress increases from the centerline towards the two sides before gradually decreasing after reaching the peak. At a distance of $1.27 D$ from the tunnel face (where $D$ is the diameter of the tunnel), the lateral additional stress approaches zero. The influence range is approximately $1.3 \mathrm{D}$ on both sides of the centerline of the tunnel. 


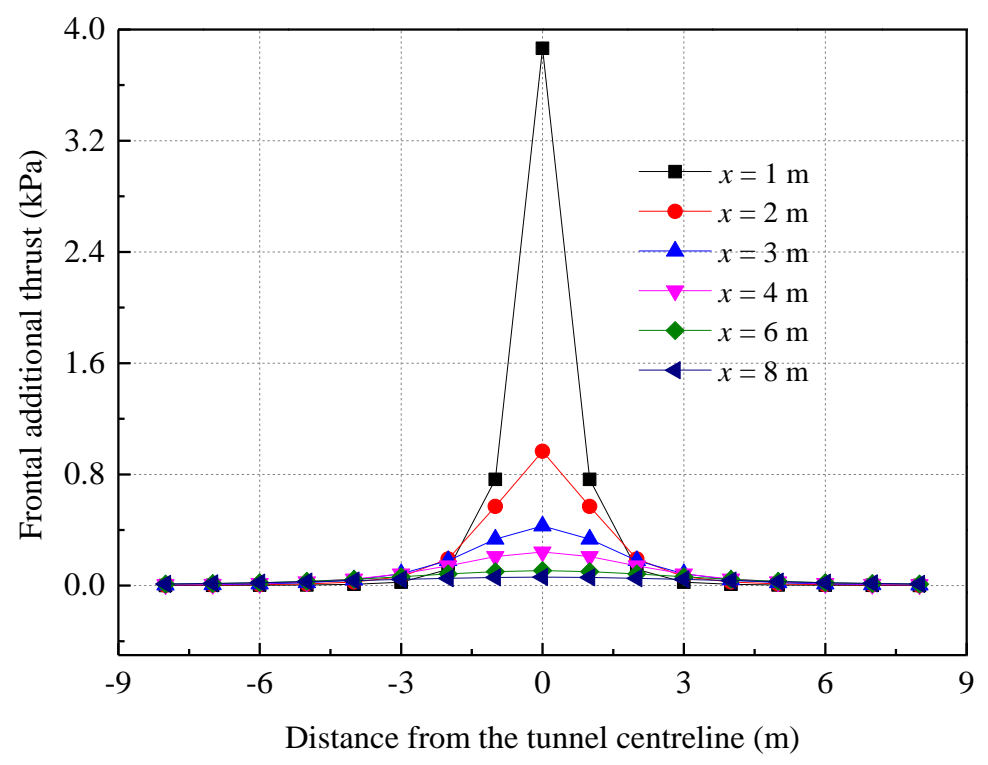

Figure 4. Variation in the frontal additional stress $\sigma_{x}$ along the $y$ direction.

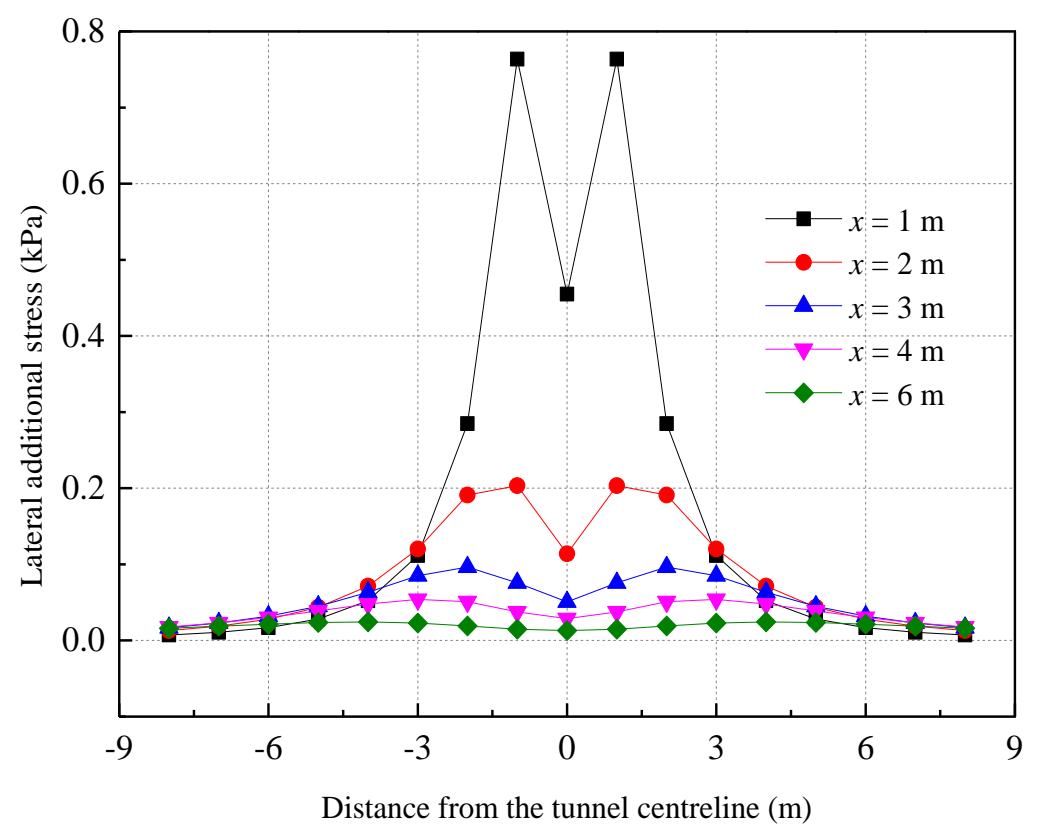

Figure 5. Variation in the lateral additional stress $\sigma_{y}$ along the $y$ direction.

\subsubsection{Friction between the Shield Shell and the Soil}

Because the size of the shield shell is larger than the cutterhead, over-excavation may occur during construction, leading to a gap between the shield shell and the surrounding soil. Meanwhile, the soil will become loose and move to the inside of the tunnel because of stress release in the soil. In this paper, the Rankine active earth pressure is used to calculate the earth pressure at the axis of the shield shell. The calculation formula for the Rankine active earth pressure at a certain depth is as follows:

$$
\sigma_{a}=K_{a} \sum_{i=1}^{n} \gamma_{i} \Delta h_{i}-2 c \sqrt{K_{a}}
$$

where $\gamma_{i}$ is unit weight (in $\mathrm{kN} / \mathrm{m}^{3}$ ), $K_{a}$ is the main dynamic earth pressure coefficient, $c$ is the cohesive of soil layer (in $\mathrm{kPa}$ ), $h_{i}$ is the thickness of the layer soil (in $\mathrm{m}$ ), and $n$ is the number of soil layers from the ground to the depth $\mathrm{z}$ below the ground. 
The buried depth of the tunnel is approximately $14 \mathrm{~m}$ in the construction regions, and the soil layer is mainly composed of backfill soil, medium sand, coarse sand, etc. It is assumed that the friction force between the shield shell and the soil is evenly distributed, and the friction coefficient $f$ is 0.3 . According to the geological data, the soil layer of the shield excavation face is mainly a permeable layer. Therefore, when calculating the Rankine active soil pressure, the method of separate calculations for the water and soil pressures should be used, and $K_{a 1}=0.70, K_{a 2}=0.59, K_{a 3}=0.29$.

Based on Equations (19)-(22) as follows:

$$
\begin{gathered}
\sigma_{a}=K_{a i} \sum_{i=1}^{n} \gamma_{i} \Delta h_{i}-2 c \sqrt{K_{a i}}=54.34 \mathrm{kPa}, \\
P_{w}=\gamma_{w} h=10 \times 10=100 \mathrm{kPa}, \\
P=\sigma_{a}+P_{w}=154.34 \mathrm{kPa}, \\
P_{2}=f P=0.3 \times 154.34=46.3 \mathrm{kPa} .
\end{gathered}
$$

Figure 6 shows that the additional stress increases near the tunnel face but rapidly decreases at both the sides of the centerline and has a small influence range. The stress value is smaller farther from the tunnel face, and the amplitude at both sides is also smaller, but its influence range is larger. The maximum value appears at the centerline of the shield tunnel. At a distance of $1 \mathrm{~m}$ from the tunnel face, the maximum additional stress is $17.6 \mathrm{kPa}$, and the influence range is mainly within approximately 1.3 $D$ from the tunnel center line.

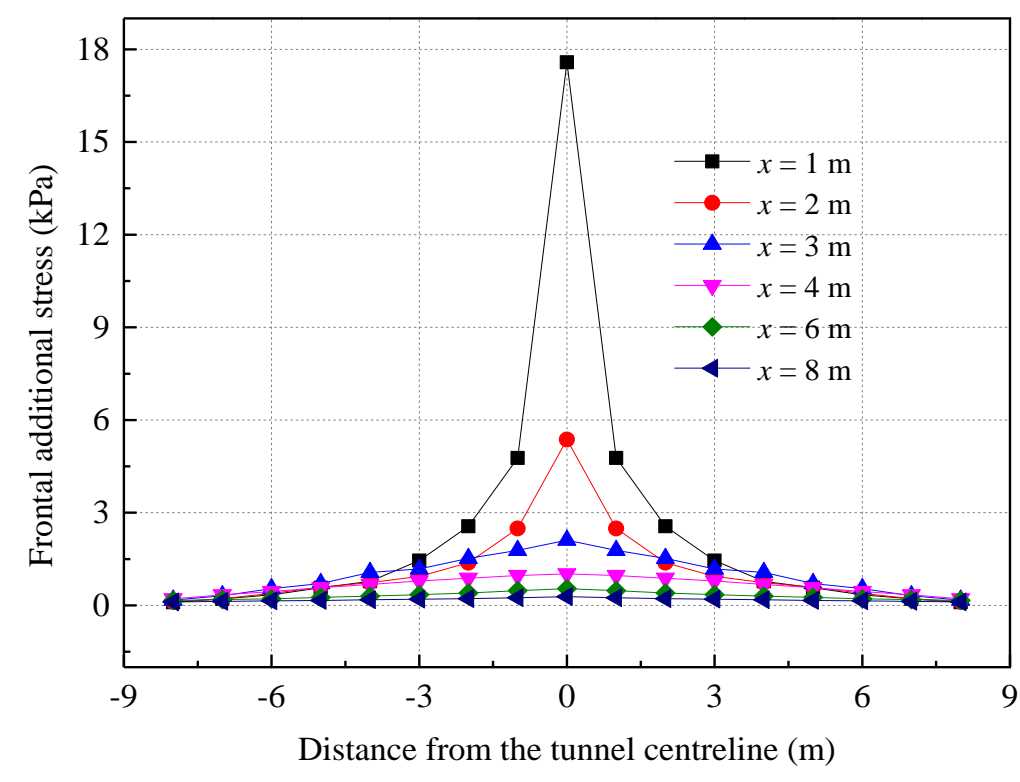

Figure 6. Variation in the frontal additional stress $\sigma_{x}$ along the $y$ direction.

The distribution curve of the lateral additional stress $\sigma_{y}$ caused by friction between the shield shell and the soil is shown in Figure 7 along the $y$ direction. The lateral additional stress $\sigma_{y}$ is symmetrically distributed on the centerline of the shield tunnel. The additional stress zone appears within a range from approximately $2 \mathrm{~m}$ on both sides of the centerline of the tunnel, and the influence range is approximately $1.67 \mathrm{D} \mathrm{m}$ on both sides of the centerline of the tunnel. There is an obvious peak and takes on a compressive stress near the centerline of the tunnel but gradually increases to zero as the distance from the centerline of the tunnel increases. 


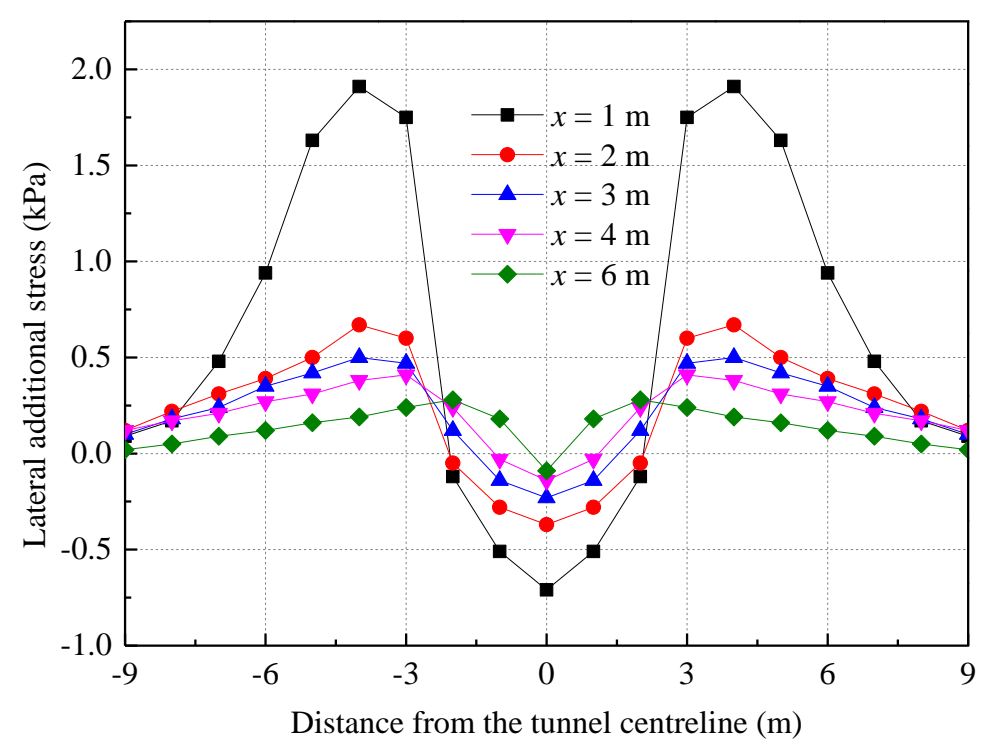

Figure 7. Variation in the lateral additional stress $\sigma_{y}$ along the $y$ direction.

\subsubsection{The Ground Loss}

The distribution curve of the frontal additional stress caused by soil loss is shown in Figure 8 along the $y$ direction. The additional stress is symmetrically distributed around the centerline of the tunnel. At areas closer to the tunnel face, greater additional stresses are observed that rapidly decrease and have a gradually smaller influence range farther from the centerline of the tunnel. At a distance of $1 \mathrm{~m}$ from front of the tunnel plane, the frontal additional stress reaches a peak of approximately $3.8 \mathrm{kPa}$ and rapidly decreases at both sides, but the influence range is large.

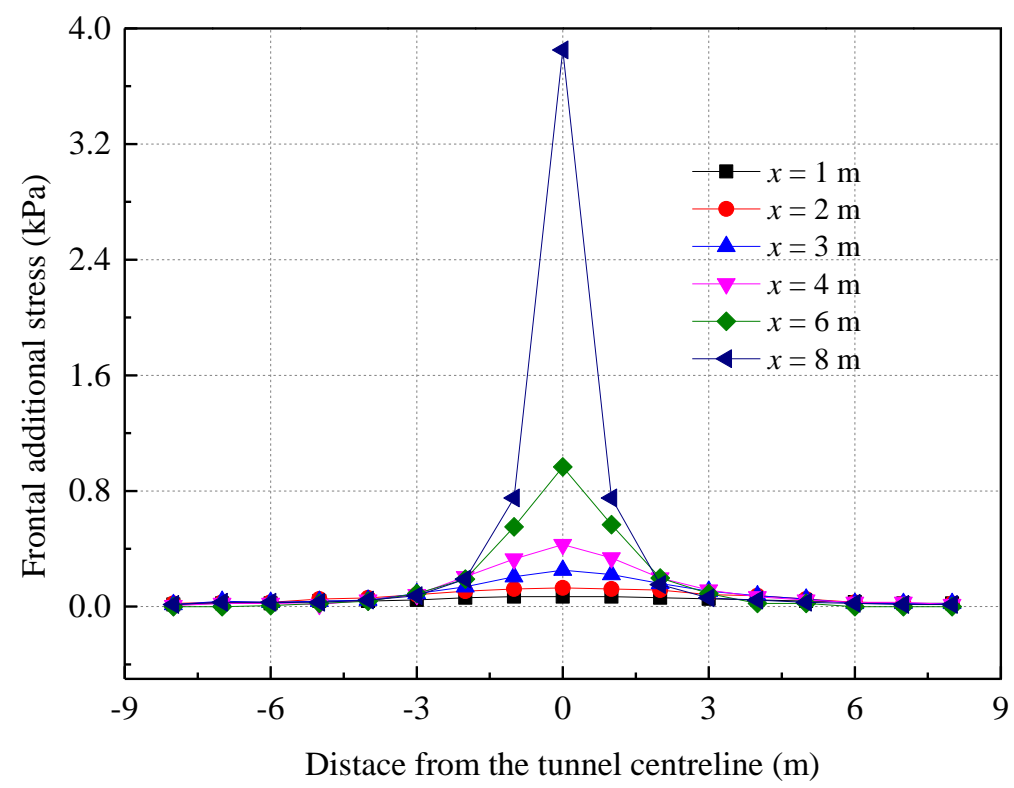

Figure 8. Variation in the frontal additional stress $\sigma_{x}$ along the $y$ direction.

The distribution curve of the lateral additional stress caused by ground loss is shown in Figure 9 in the excavation direction of the tunnel. The additional stress is distributed symmetrically along the axis of the shield. At areas closer to the tunnel face, greater additional stresses are seen. At a distance of $1 \mathrm{~m}$ from front of the tunnel face, the maximum lateral additional stress is $1.3 \mathrm{kPa}$ on the centerline of the tunnel that gradually decreases from the centerline along both sides. At a distance of 
approximately $4 \mathrm{~m}$ from the centerline of the tunnel, there is an obvious peak and a compressive stress near the centerline of the tunnel. This gradually increases to zero with distance from the centerline of the tunnel.

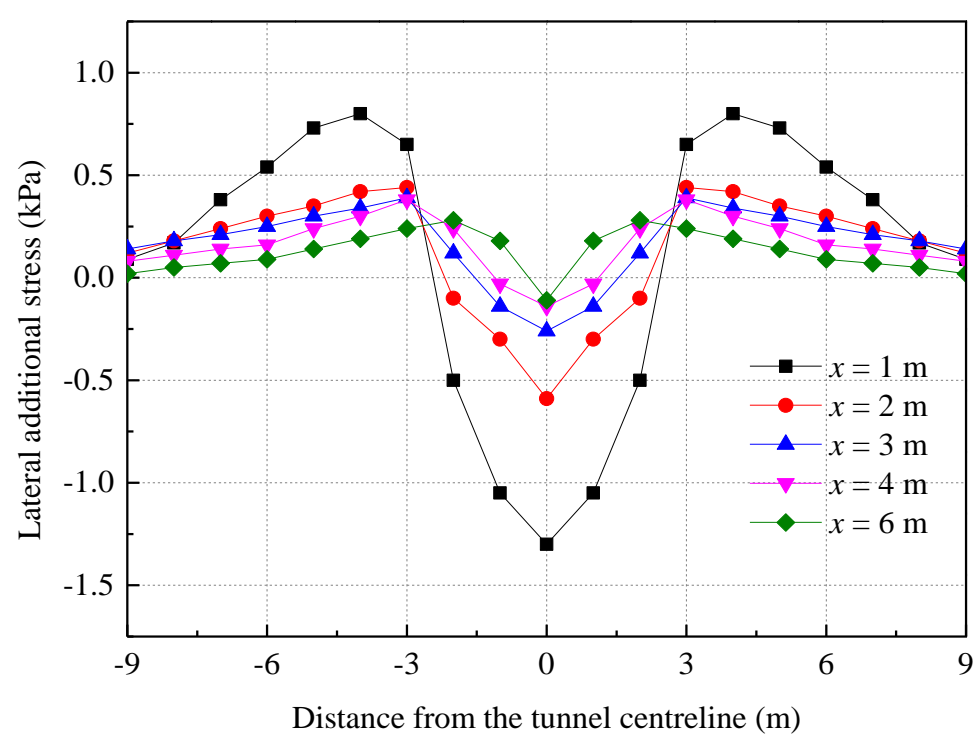

Figure 9. Variation in the lateral additional stress $\sigma_{y}$ along $y$ direction.

\subsubsection{The Additional Stress under the Combined Action of the Three Factors}

By superimposing the additional stress of the abovementioned factors, a total additional stress distribution curve is obtained, as shown in Figures 10 and 11. The trend of the curves is similar to that of stress induced by the aforementioned single factor. The additional stress caused by friction between the shield shell and the soil is larger and accounts for approximately $70.7 \%$ of the total additional stress. The additional stress caused by the additional thrust and the ground loss is smaller and accounts for approximately $15.2 \%$ and $14.1 \%$, respectively. The lateral friction accounts for $69.1 \%$ of the total lateral additional stress, and the frontal additional thrust and soil loss account for $2.9 \%$ and $28 \%$, respectively.

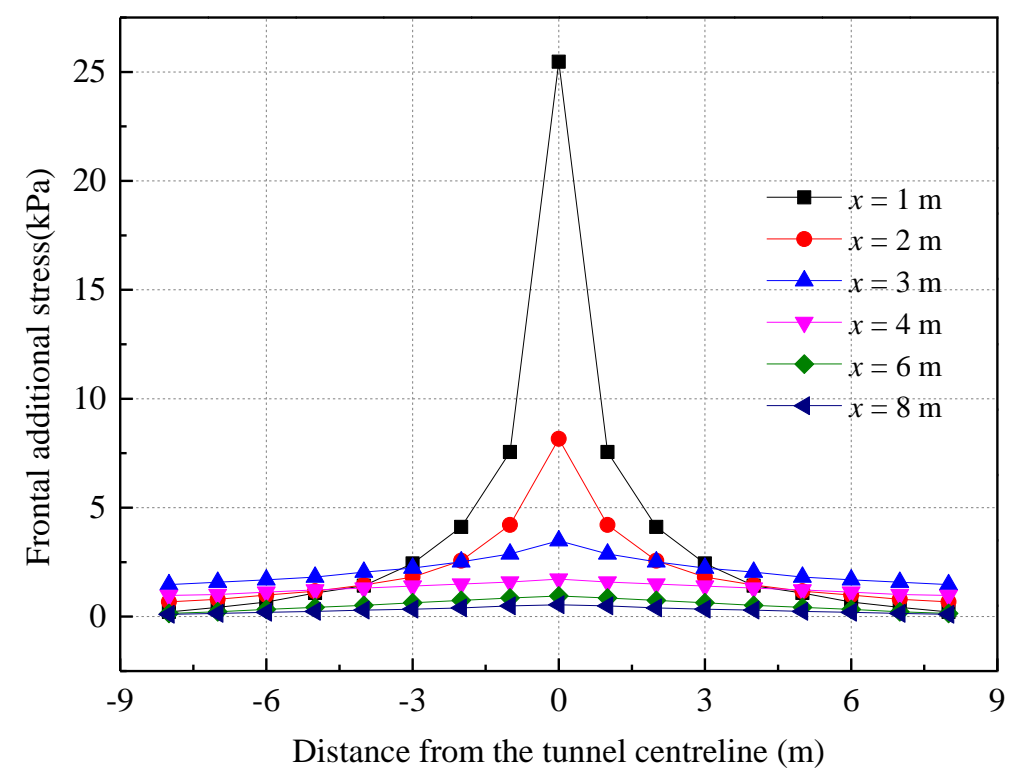

Figure 10. Variation in the frontal additional stress $\sigma_{x}$ along the $y$ direction. 


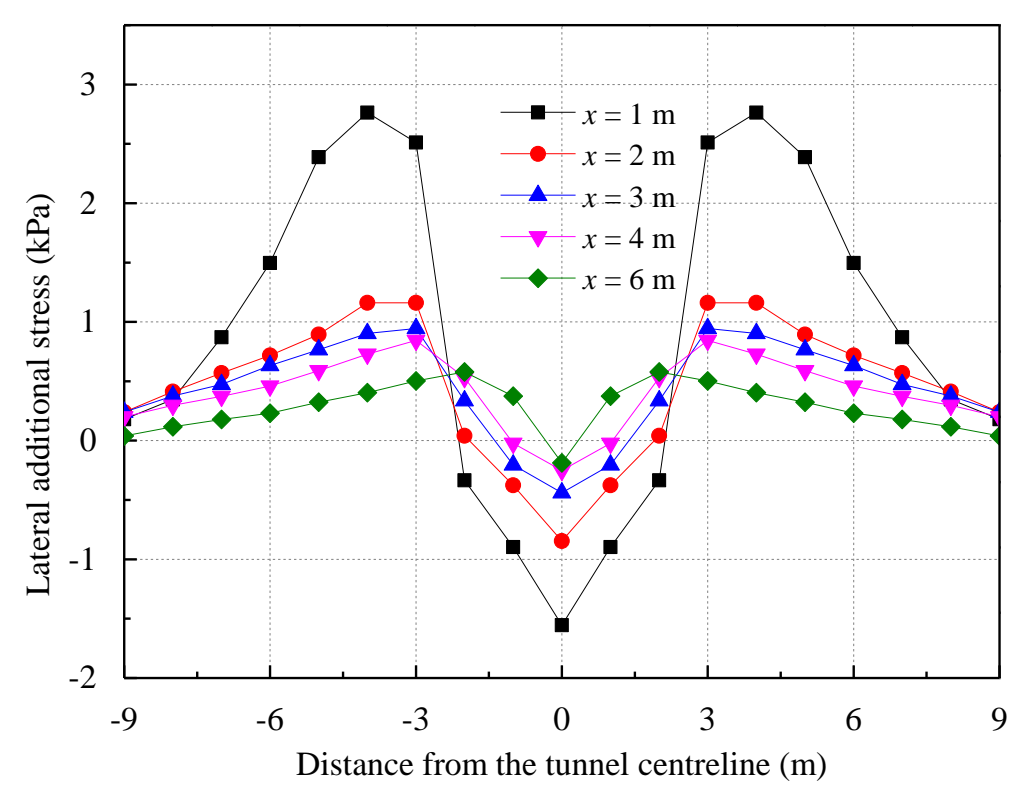

Figure 11. Variation in the lateral additional stress $\sigma_{y}$ along the $y$ direction.

\section{Ground Surface Settlement Law over the Shield Tunnel}

\subsection{Monitoring Scheme}

The arrangements for ground settlement monitoring are illustrated in Figure 12. In each cross-section, 12 ground settlement gauges were installed to record the vertical settlements at different positions. The distances between the different gauges at sections $\mathrm{K} 28+773$ and $\mathrm{K} 28+803$ are the same as in section $\mathrm{K} 28+744$. The process for settlement gauge installation is shown as Figure 13. At first, a hole was bored from the ground surface with a percussion drill to a depth sufficient to reach the original stratum. After that, the settlement gauge was embedded in the hole and filled with dense sand. The ground settlement was measured six times per day (once every $4 \mathrm{~h}$ ) until the shield absolutely passed through the three selected sections and the ground settlement stabilized.

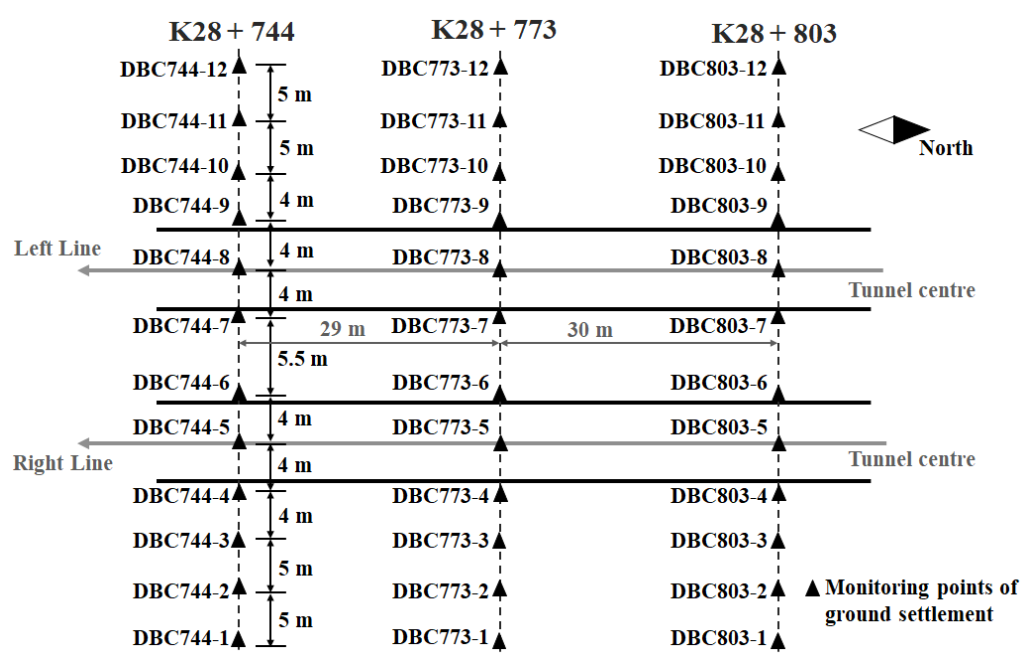

Figure 12. The layout of monitoring points. 


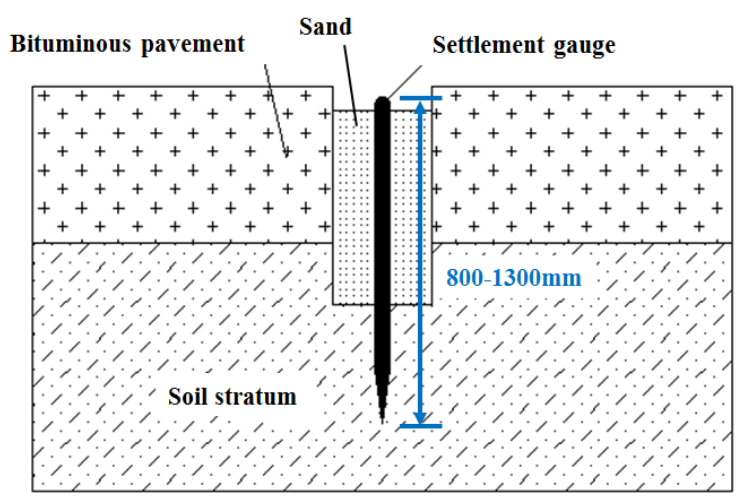

Figure 13. Layout of the monitoring points.

\subsection{The Modified Peck Formula}

\subsubsection{Construction Process of the Support Structure}

Using the construction of the Wenjing running tunnel as an example, the excavation area of the single-line tunnel is approximately $30.96 \mathrm{~m}^{2}$, the ground loss rate is $0.5 \%$, and the buried depth of the tunnel is approximately $19.274 \mathrm{~m}$. Based on the typical Peck formula [15] and field measurements, the curvature of the ground surface settlements and Peck deformations are compared, as shown in Figure 14. The trend for the ground surface settlement is basically the same for the three monitoring sections, but there is a large gap between the predicted value of the typical Peck formula and that of the three monitoring sections. Therefore, the typical Peck curve needs to be modified.

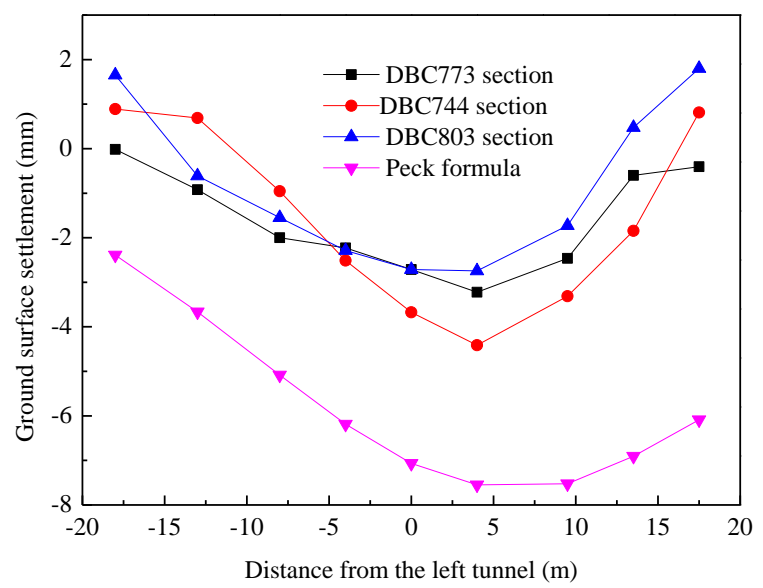

Figure 14. Comparison of the lateral ground surface settlements.

\subsubsection{Construction Process of the Support Structure}

Using the monitoring sections (e.g., DBC773 and DBC744), the Origin software package is used to fit the settlement data and to obtain Equation (23). Simultaneously, considering the superposition effect and regional influence of the double-O-tube tunnel, the coefficients of the maximum surface settlement and the width settlement trough width are modified in view of the Peck formula. It is assumed that the coefficients of correction are $k_{1}, k_{2}$, and $k_{3}$, which are used to obtain the following Equation (24), and the fitting parameters and correlation coefficients are shown in Table 3.

$$
\begin{gathered}
S(x)=A \exp \left(-x^{2} / 2 i^{2}\right)+B \exp \left[-(x-13.2)^{2} / 2 i^{2}\right] \\
S(x)=k_{1} S(x)_{\max } \exp \left(-x^{2} / 2 \cdot k_{3} \cdot i^{2}\right)+k_{2} S(x)_{\max } \exp \left[-(x-L)^{2} / 2 \cdot k_{3} \cdot i^{2}\right] .
\end{gathered}
$$


Table 3. Fitting parameters and correlation coefficients.

\begin{tabular}{ccccccccc}
\hline Monitoring Points & $\boldsymbol{A}$ & $\boldsymbol{B}$ & $\boldsymbol{i}$ & $\boldsymbol{R}^{\mathbf{2}}$ & $\boldsymbol{k}_{\mathbf{1}}$ & $\boldsymbol{k}_{\mathbf{2}}$ & $\boldsymbol{k}_{\mathbf{3}}$ & $\boldsymbol{R}^{\mathbf{2}}$ \\
\hline DBC773 & 2.986 & 1.097 & 7.034 & 0.80 & 0.71 & 0.26 & 0.48 & 0.83 \\
DBC744 & 4.307 & 1.162 & 6.157 & 0.84 & 1.02 & 0.27 & 0.42 & 0.86 \\
\hline
\end{tabular}

The curves for the typical Peck formula, modified Peck curve, and field measurements are shown in Figure 15. The ground surface settlement obtained from the typical Peck formula is relatively large, and the modified Peck settlement curve is in good agreement with the field measurements, meaning that the ground surface settlement caused by the shield construction can be predicted more accurately.

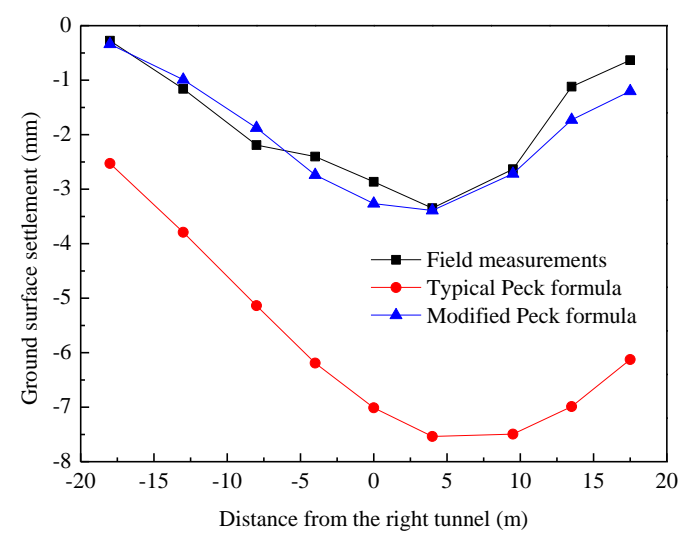

(a)

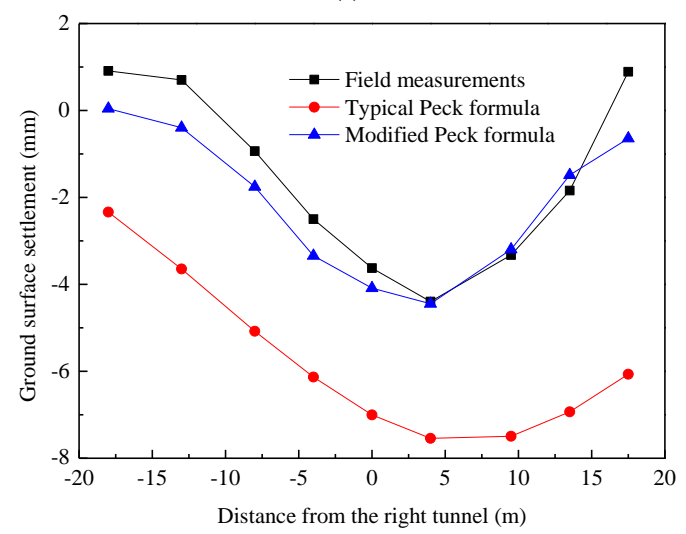

(b)

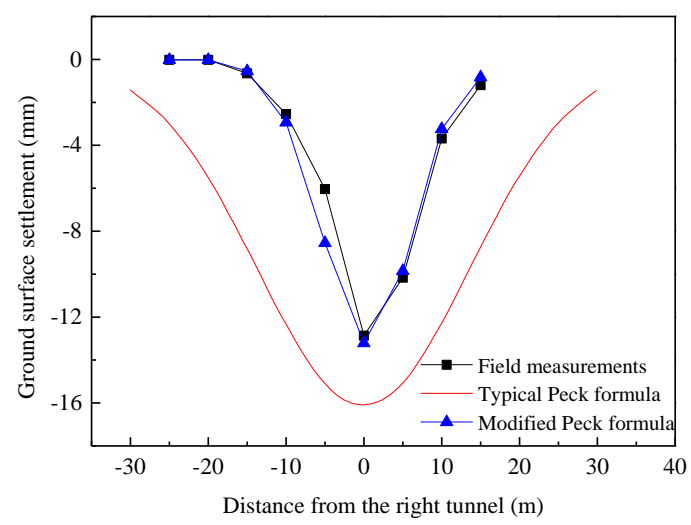

(c)

Figure 15. Comparison of the lateral ground surface settlements. (a) DBC773 section, (b) DBC744 section, (c) the reference [7]. 


\subsection{Shape of the Ground Surface Settlement Curve}

\subsubsection{Finite Element Model}

Finite element models are established to investigate the shape of ground surface settlement curves using Madis/GTS. The excavation diameter of the tunnel is $6 \mathrm{~m}$, and the dimensions of the numerical model are $60 \mathrm{~m} \times 40 \mathrm{~m}$, which are used to reduce the boundary effect. The bottom and lateral surfaces are fixed, and the top surface is free, as shown in Figure 16. In total, 2526 zones are used, meanwhile the element size is approximately $1 \mathrm{~m} \times 1 \mathrm{~m}$. For simplicity, the Mohr-Coulomb model is adopted to define the behavior of the natural and improved soil in the numerical analyses, and the calculation parameters of the soil layers are shown in Table 4. The cohesions and friction angles of sandy soils are obtained according to the recommended relationship between the strength parameter and DPSH (Dynamic Probing Super Heavy) value from the scientific references. Additionally, the cohesions (c) are usually negligible for the sandy soil based on engineering experience and some scientific references. However, for the numerical simulation software, $\mathrm{c}=0$ may cause some options to hardly perform, even the calculation of non-convergence. Therefore, the cohesions of sandy soils are generally assumed to be $1 \mathrm{kPa}$ in the numerical analysis [36-38]. The segment is deemed to have a liner-elastic behavior, and the main mechanical parameters of the structure are shown in Table 5. The interface elements are used to simulate the interaction between soil and structure.

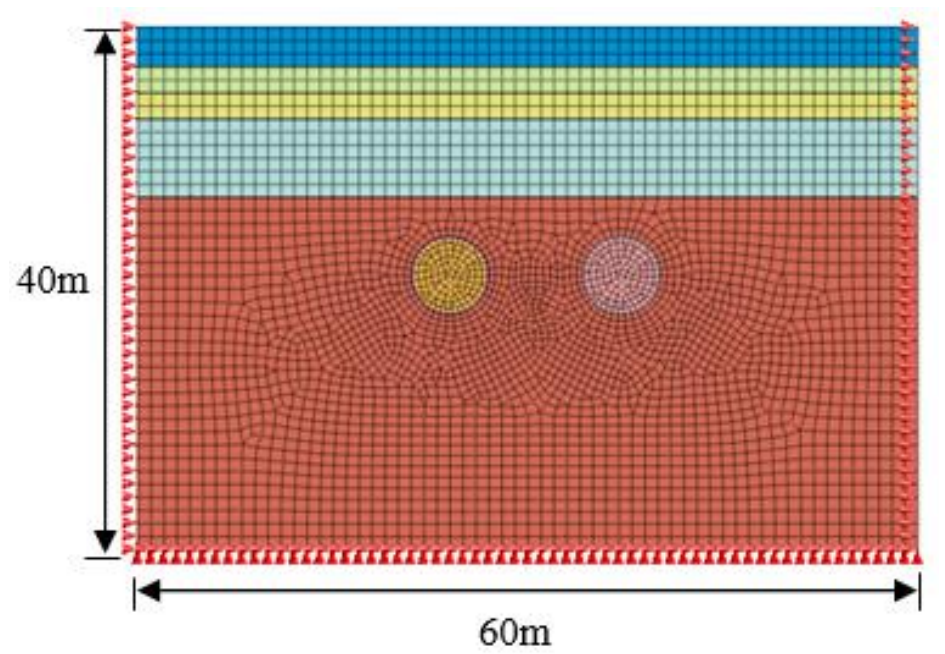

Figure 16. The finite element model.

Table 4. Physical and mechanical parameters of the soil.

\begin{tabular}{|c|c|c|c|c|c|c|}
\hline Soil Layer & $\begin{array}{c}\text { Soil } \\
\text { Thickness } \\
\text { (m) }\end{array}$ & $\begin{array}{l}\text { Unit Weight } \\
\left(\mathbf{k N} \cdot \mathrm{m}^{-3}\right)\end{array}$ & $\begin{array}{l}\text { Deformation } \\
\text { Modulus } \\
\text { (MPa) }\end{array}$ & $\begin{array}{c}\text { Poisson } \\
\text { Ratio }\end{array}$ & $\begin{array}{l}\text { Cohesion } \\
\text { (kPa) }\end{array}$ & $\begin{array}{l}\text { Internal } \\
\text { Friction } \\
\text { Angle }\left(^{\circ}\right)\end{array}$ \\
\hline Filled soil & 3 & 18 & 7 & 0.25 & 3 & 8 \\
\hline Silty clay & 2 & 20 & 13 & 0.3 & 32 & 26.5 \\
\hline Silty sand & 2 & 20 & 18 & 0.26 & 1 & 30 \\
\hline Medium-coarse sand & 6 & 20.7 & 20 & 0.27 & 1 & 32 \\
\hline Coarse sand & 27 & 20.8 & 23 & 0.28 & 1 & 34 \\
\hline
\end{tabular}

Table 5. Structural material parameters.

\begin{tabular}{cccc}
\hline Parameters & $\begin{array}{c}\text { Unit Weight } \\
\mathbf{( k N} \cdot \mathbf{m}^{-3} \mathbf{)}\end{array}$ & $\begin{array}{c}\text { Elastic Modulus } \\
\mathbf{( G P a )}\end{array}$ & Poisson Ratio \\
\hline Segment & 25 & 31.5 & 0.2 \\
\hline
\end{tabular}




\subsubsection{Settlement Pattern of the Tunnel}

The settlement curve for the tunnel is shown in Figure 17. The maximum settlement point appears over the center of the tunnel after the excavation of the left line. The maximum ground surface settlement is $3.72 \mathrm{~mm}$, and the surface settlement curve obeys the deformation law of Peck's settlement trough. After the right line is excavated, the maximum settlement point $(5.72 \mathrm{~mm})$ stabilizes at approximately $6 \mathrm{~m}$ away from centerline of the left line tunnel. The maximum settlement is $5.72 \mathrm{~mm}$, which is approximately $53.8 \%$ larger than the maximum settlement caused by a single-line tunnel, meaning that the settlement influence range clearly increases. The settlement curve shows that the single peak settlement trough still conforms to the deformation law.

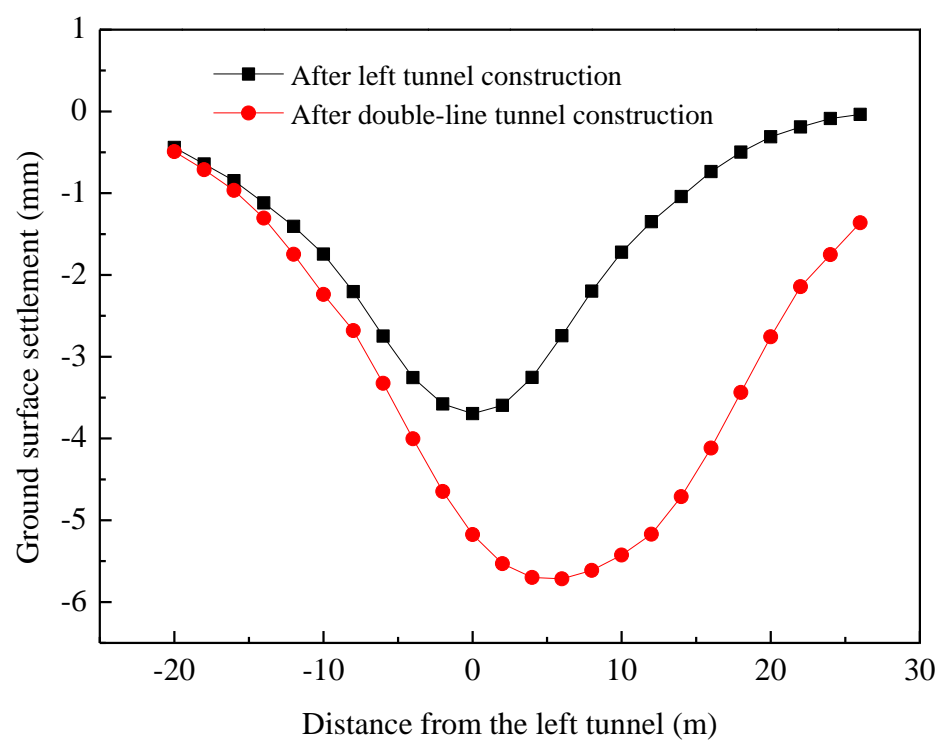

Figure 17. Ground surface settlement curves.

\subsubsection{The Influence of Burial Depth and Spacing on the Surface Settlement}

To study the influence of burial depth and spacing on the surface settlement curve, the cut-off standard of the single and double peaks are obtained for the surface settlement curve. A total of 16 different conditions are designed, as shown in Table 6. The cross section of the double-O-tube tunnel is shown in Figure 18. The left line tunnel is first to be excavated, followed by the right line tunnel.

When the burial depth is relatively shallow, the tunnel spacing has a great impact on the ground settlement. When the tunnel spacing increases by $0.1 \mathrm{D}$, the ground surface settlement subsequently decreases by approximately $23 \%$, as shown in Figure 19a. As the burial depth increases, the ground settlement gradually increases, but the effect of tunnel spacing on the sensitivity of ground surface settlement decreases. When the tunnel spacing increases by $0.1 \mathrm{D}$, the decrease in the ground surface settlement is within $7 \%$. The range of the decrease for the maximum settlement clearly decreases during tunnel construction, but the influence range of the settlement increases, as shown in Figure 19b-d. This is due to the burial depth reaching a certain degree where the soil forms a soil arch effect, which slows down ground settlement $[39,40]$.

Table 6. Parameters of the tunnel location.

\begin{tabular}{ccccc}
\hline Tunnel location & \multicolumn{3}{c}{ L/D } \\
\hline Z/D & $(1.0,0.5)$ & $(2.0,1.1)$ & $(2.5,1.5)$ & $(3.0,2.0)$ \\
& $(1.0,0.6)$ & $(2.0,1.2)$ & $(2.5,1.6)$ & $(3.0,2.1)$ \\
& $(1.0,0.7)$ & $(2.0,1.3)$ & $(2.5,1.7)$ & $(3.0,2.2)$ \\
& & $(2.0,1.4)$ & $(2.5,1.8)$ & $(3.0,2.3)$ \\
\hline
\end{tabular}




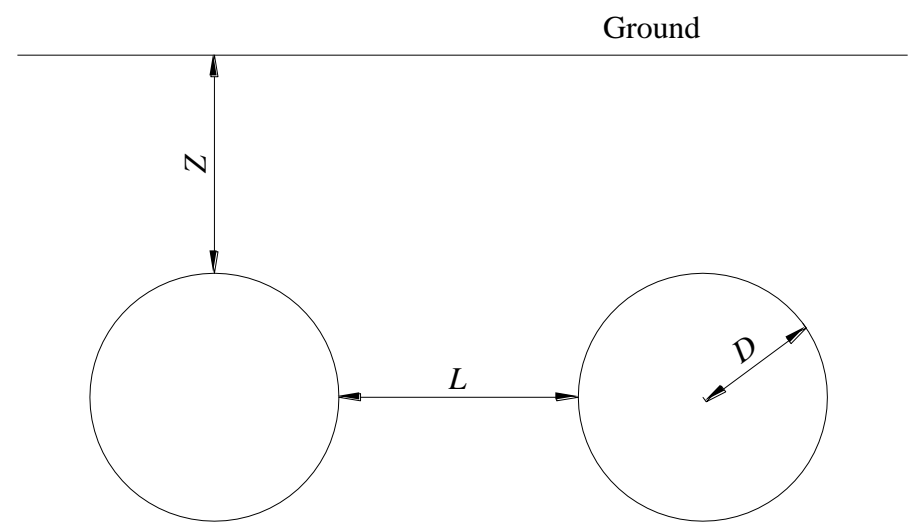

Figure 18. Layout of the double-O-tube tunnel.

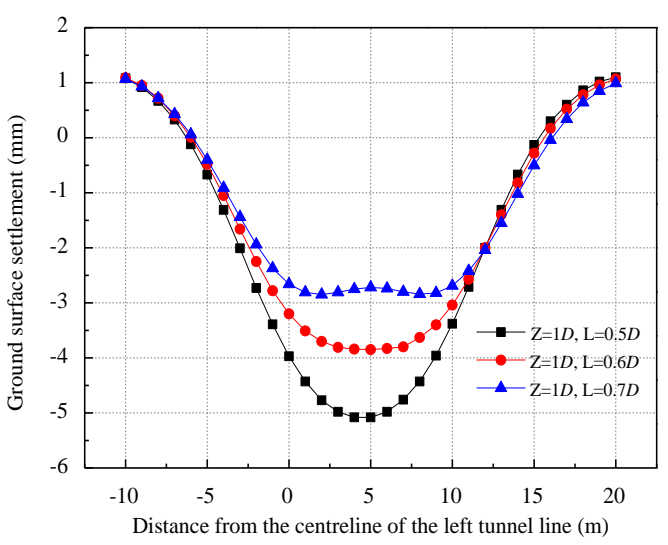

(a)

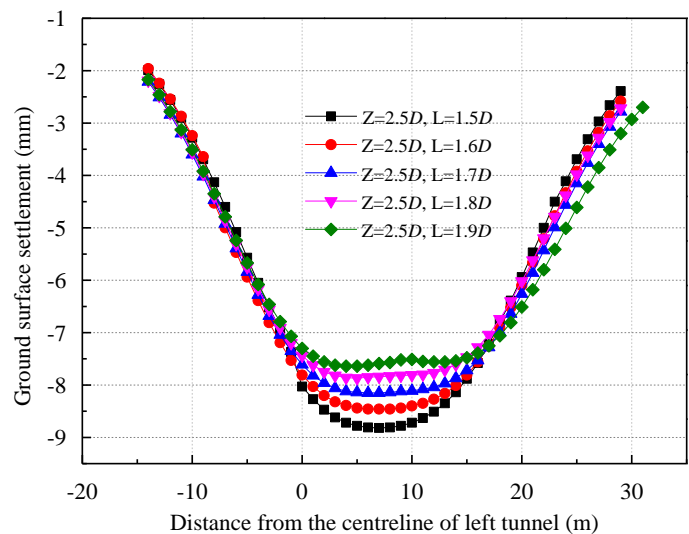

(c)

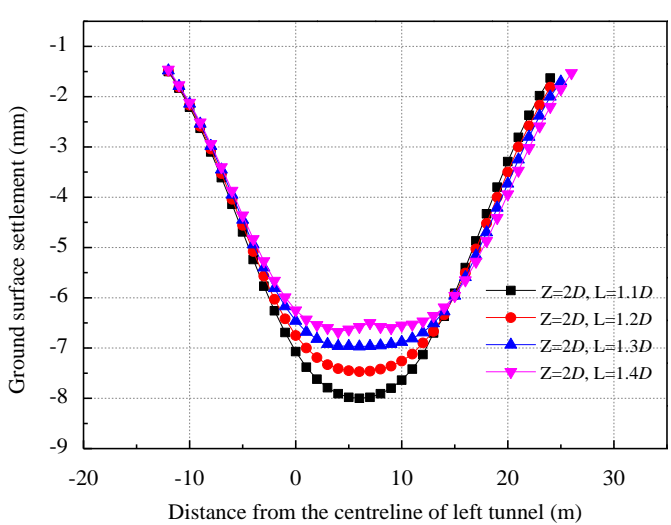

(b)

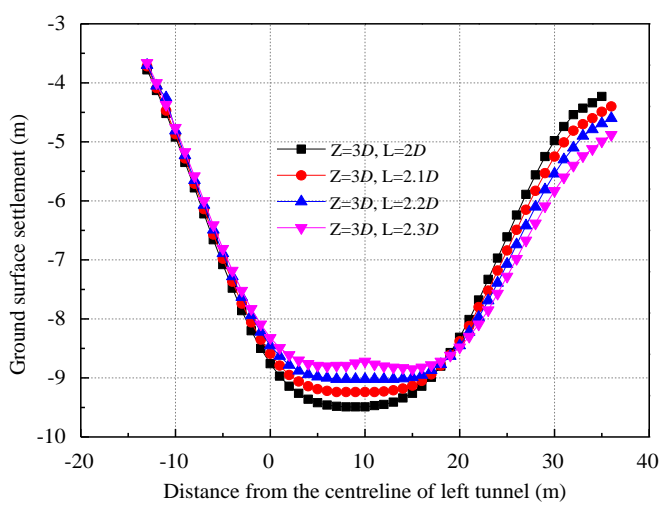

(d)

Figure 19. Ground surface settlement under different buried depth and spacing: (a) $1.0 \mathrm{D}$; (b) $2.0 \mathrm{D}$; (c) $2.5 \mathrm{D} ;$ (d) $3.0 \mathrm{D}$.

For double-O-tube tunnels, the ground settlement curve is superimposed by the settlement caused by the two single tunnels. When the buried depth remains unchanged, the shape of the settlement curve will change as the tunnel spacing changes. Based on the above 16 conditions, single and double peak boundary points for the ground surface settlement curves caused by the construction of a double-O-tube tunnel are summarized. The cut-off function, shown in Equation (25), is obtained by fitting as follows:

$$
y=0.81 x-0.24
$$


When the coordinate point is located at the lower side of the fitting curve, the ground surface settlement curve takes on a single peak state. Otherwise, the ground surface settlement curve takes on a two-peak form, as shown in Figure 20. According to the engineering case described here, $Z / D=2.71$ and $L / D=1.03$ are obtained, and the coordinate point is located at the lower side of the fitting curve. According to Equation (25), it can be predict that the ground surface settlement curve is a single-peak, which is consistent with the surface settlement curve determined from field measurements. This proves the correctness and rationality of the cut-off function proposed here.

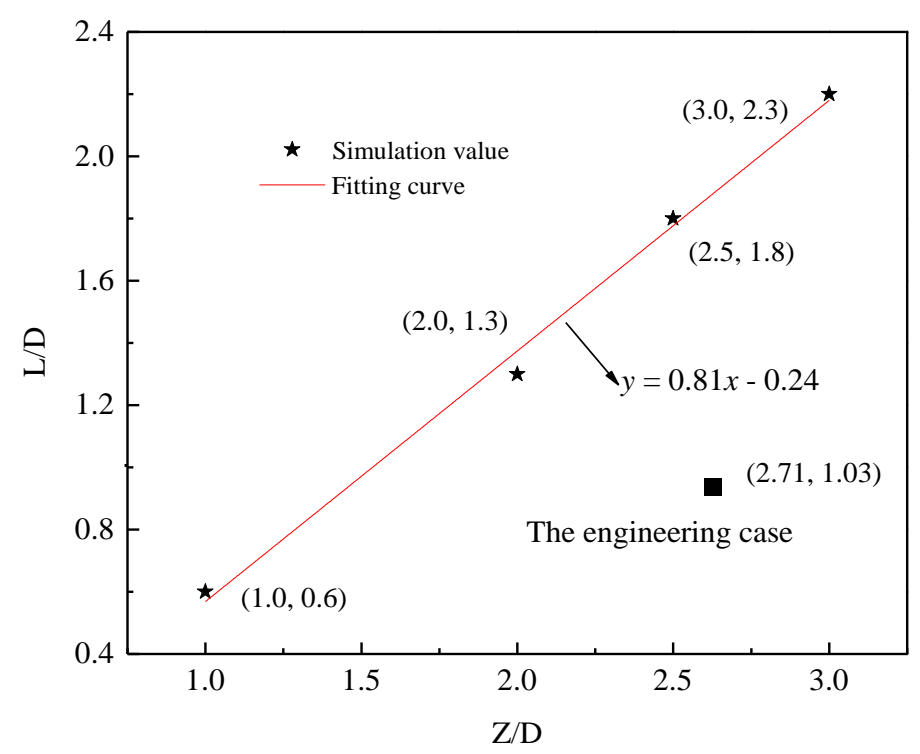

Figure 20. Fitting curve for the cut-off points of the single and double-O-tube tunnel.

4.3.4. The Influence of the Soil Layer Parameters on the Shape of the Surface Settlement Curve

This paper studies the influence of the soil layers parameters on the shape of the ground settlement to obtain a cut-off standard for single and double peaks. Based on more than 100 numerical calculation results, the cut-off functions for the ground surface settlements are obtained for different elastic moduli and cohesive strengths.

1) Elastic modulus

Sands with three different elastic moduli are selected for numerical analysis. Figure 21 shows that the slope of the cut-off function increases with the increase of the elastic modulus. For a double-O-tube tunnel with a small buried depth and small spacing, the elastic modulus has little effect on the cut-off function. However, as the buried depth and spacing increases, the cut-off regions for the single-peak and double-peak begin to exhibit obvious differences. For a constant burial depth, larger elastic moduli cause larger ground surface settlements for single peaks. For a constant tunnel spacing, smaller elastic moduli cause smaller ground surface settlements for single peaks. 


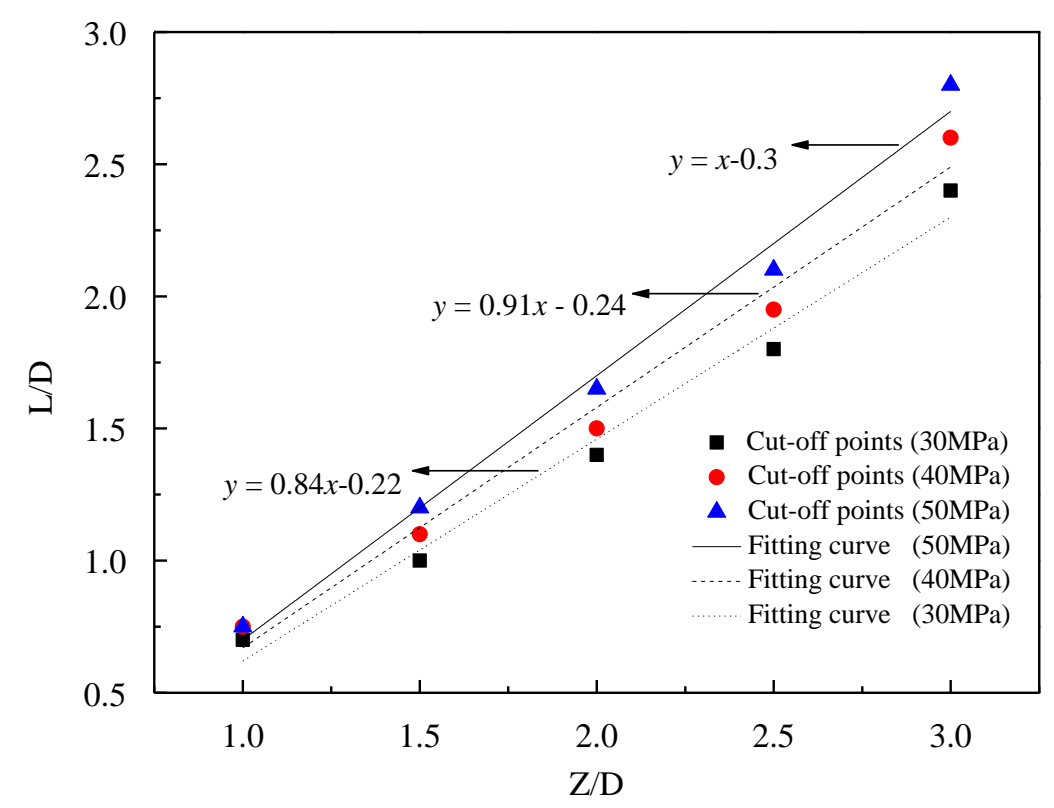

Figure 21. Fitting the cut-off function for different elastic moduli values.

2) Cohesive strength

Clays with three different cohesive strengths are used to investigate to the effect of cohesive strength on the shape of the ground surface settlement. The results in Figure 22 show that the slopes of the cut-off functions are almost the same for the different cohesive strengths. For a constant burial depth, smaller cohesive strengths cause larger ground surface settlements for single peaks. For a constant tunnel spacing, greater cohesion results in smaller ground surface settlements for single peaks. Based on the functional relationship proposed in this paper, the parameters related to the engineering case $(\mathrm{Z} / \mathrm{D}=2.71, \mathrm{~L} / \mathrm{D}=1.03)$ are substituted into the boundary function for the sand, which is located on the lower side of the function and is in good agreement with the field measurement data. This result proves that the cut-off function is reasonable and correct.

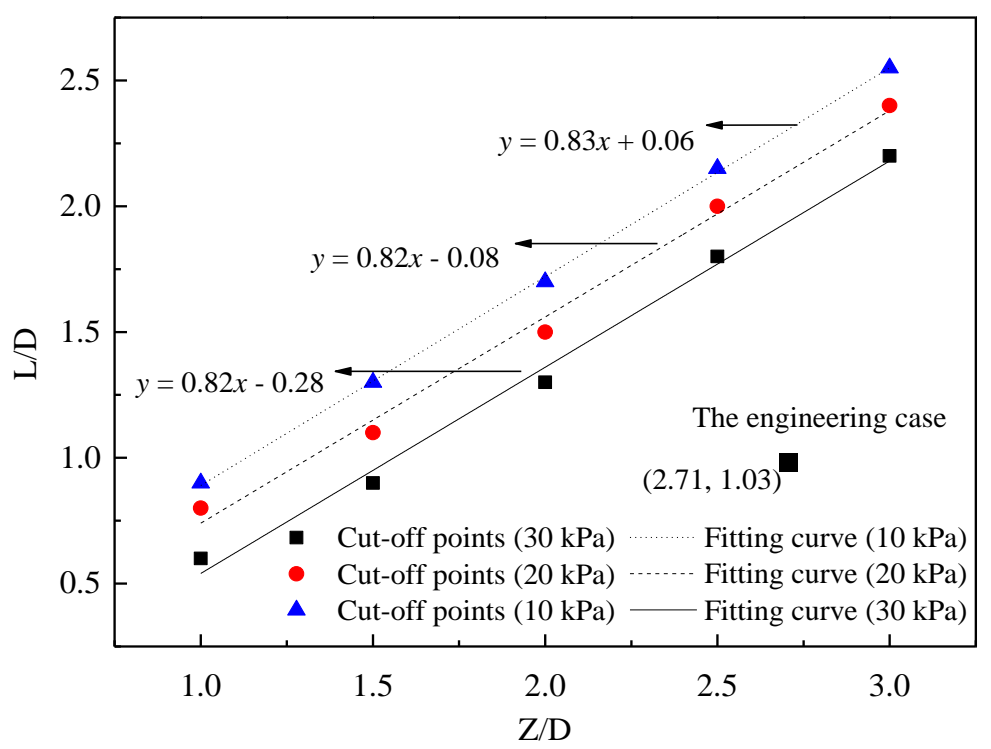

Figure 22. Fitting cut-off function for different cohesive strengths. 


\section{Conclusion}

1) Along the direction of shield excavation, the additional stress over the peak value at a range of $1.3 D \sim 1.67 D$ from the tunnel face (where $D$ is the diameter of the double-O-tube shield tunnel, $6.0 \mathrm{~m}$ ) gradually diffuses to both ends. Meanwhile, the magnitude of the additional stress gradually decreases with the increase of the distance from the tunnel face. Vertically, to the direction of the shield excavation, the frontal or lateral additional stresses are symmetrically distributed along the axis of the shield tunnel. The outcome makes it clear that the soil disturbance of the shield has regional characteristics, such as drag and extrusion above the sea-gulled segment and extrusion and friction acting laterally to the shield skin.

2) The stress is mainly frontal additional stress in the soil, and the variety of frontal additional stress is much greater than the lateral additional stress. The lateral friction is the main factor causing the additional stress and accounting for $70.7 \%$ of the total frontal additional stress (whereas the frontal additional thrust and soil loss account for $15.2 \%$ and $14.1 \%$, respectively). The lateral friction accounts for $69.1 \%$ of the total lateral additional stress, and the frontal additional thrust and soil loss account for $2.9 \%$ and $28 \%$, respectively.

3) Based on field measurements, the maximum settlement coefficient and width of the settlement trough coefficient for the typical Peck formula are modified. The prediction curve for the Peck's formula is closer to the engineering measured data than the typical formula.

4) The cut-off functions for the ground surface settlement caused by a double-O-tube tunnel shield construction are proposed and found to be able to predict the shape of ground surface settlements, such as single or double peaks. The validity of the proposed functions is verified based on the selected engineering project. When the burial depth is unchanged for larger elastic moduli, larger single-peak settlement curve areas are observed, and for smaller cohesion, greater single-peak settlement curve areas are observed.

Author Contributions: In this study, the concepts and designs were provided by P.-j.J. and W.Z. Monitoring analysis was conducted by C.C. and J.H., and data and simulation results were analyzed and examined by P.-j.J. and Y.C. Numerical simulations were conducted by L.Z. and Z.-g.W.

Funding: The research described in this paper was supported by the National Science Foundation of China (No. 51578116, No. 51878127) and the China Scholarship Council (No. 201706080089). These supports are gratefully acknowledged. And the data is available for the journal.

Acknowledgments: The authors would like to thank Northeastern University in providing the access to the software and other facilities.

Conflicts of Interest: The authors declare no conflict of interest.

\section{References}

1. Broere, W. Urban underground space: Solving the problems of today's cities. Tunn. Undergr. Space Technol. 2016, 55, 245-248. [CrossRef]

2. Chena, R.P.; Lin, X.T.; Kang, X.; Zhong, Z.Q.; Liu, Y.; Zhang, P.; Wu, H.N. Deformation and stress characteristics of existing twin tunnels induced by close-distance EPBS under-crossing. Tunn. Undergr. Space Technol. 2018, 82, 468-481. [CrossRef]

3. Chen, R.P.; Zhu, J.; Liu, W.; Tang, X.W. Ground movement induced by parallel epb tunnels in silty soils. Tunn. Undergr. Space Technol. 2011, 26, 163-171. [CrossRef]

4. Meng, F.Y.; Chen, R.P.; Kang, X. Effects of tunneling-induced soil disturbance on the post-construction settlement in structured soft soils. Tunn. Undergr. Space Technol. 2018, 80, 53-63. [CrossRef]

5. Li, X.G.; Chen, X.S. Using grouting of shield tunneling to reduce settlements of overlying tunnels: Case study in Shenzhen metro construction. J. Constr. Eng. Manag. 2012, 138, 574-584. [CrossRef]

6. Burland, J.B.; Worth, C.P. Settlement of Buildings and Associated Damage. In Proceedings of the International Conference on Settlement of Structures; Pentech Press: Cambridge, UK; London, UK, 1974; pp. 611-654.

7. Boscardin, M.; Cording, E. Building response to excavation-induced settlement. J. Geotech. Eng. 1989, 115, 1-21. [CrossRef] 
8. Son, M.; Cording, E.J. Estimation of building damage due to excavation induced ground movement. J. Geotech. Geoenviron. Eng. 2005, 131, 162-177. [CrossRef]

9. Celestino, T.B.; Gomes, R.A.M.P.; Bortolucci, A.A. Errors in ground distortions due to settlement trough adjustment. Tunn. Undergr. Space Technol. 2000, 15, 97-100. [CrossRef]

10. McCabe, B.A.; Orr, T.L.L.; Reilly, C.C.; Curran, B.G. Settlement trough parameters for tunnels in Irish glacial tills. Tunn. Undergr. Space Technol. 2012, 27, 1-12. [CrossRef]

11. Mohammed, Y.F.; Kais, T.S.; Nahla, S. Prediction of settlement trough induced by tunneling in cohesive ground. Acta Geotech. 2013, 8, 167-179.

12. Kolivand, F.; Rahmannejad, R. Determination of settlement trough width and optimization of soil behavior parameters based on the design of experiment method (DOE). Int. J. Min. Geo-Eng. 2018, 52, 7-15.

13. ITA/AITES WG "Research". Settlement Induced by Tunneling in SoftGround. Tunn. Undergr. Space Technol. 2007, 22, 119-149. [CrossRef]

14. Mirhabibi, A.; Soroush, A. Effects of surface buildings on twin tunneling-induced ground settlements. Tunn. Undergr. Space Technol. 2012, 29, 40-51. [CrossRef]

15. Peck, R.B. Deep excavations and tunneling in soft ground. In Proceedings of the 7th International Conference on Soil Mechanics and Foundation Engineering, Mexico City, Mexico, 1969; State of the Art Volume, pp. 225-290. Available online: https://www.issmge.org/uploads/publications/1/38/1969_03_0010.pdf (accessed on 3 April 2019).

16. Osman, A.; Bolton, M.; Mair, R. Predicting 2D ground movements around tunnels in undrained clay. Géotechnique 2006, 56, 597-604. [CrossRef]

17. Osman, A.; Mair, R.; Bolton, M. On the kinematics of 2D tunnel collapse in undrained clay. Géotechnique 2006, 56, 585-595. [CrossRef]

18. Duan, S.K.; Huang, L.; Bao, Z.; Shen, P. Application of modified Peck formula in surface subsidence prediction of Changsha subway tunnel construction. J. Nat. Disasters 2013, 24, 164-169.

19. Huang, L.; Duan, S.W.; Xie, Z.Q.; Jiang, X.L. A Revision of Peck Formula Based on the Surface Subsidence Due to Metro Excavation in Changsha. EJGE 2015, 20, 2115-2123.

20. Zhu, C.H. Control of surface settlement by considering shield tunneling technology. KSCE J. Civ. Eng. 2017, 21, 2896-2907. [CrossRef]

21. Lee, K.M.; Rowe, R.K. Analysis of the three dimensional ground movements, the Thunder Bay Tunnel. Can. Geotech. J. 1991, 28, 25-41. [CrossRef]

22. Loganathan, N.; Poulos, H.G. Analytical prediction for tunneling-induced ground movement in clays. J. Geotech. Geoenvirom. Eng. 1998, 124, 846-856. [CrossRef]

23. Jiang, X.L.; Zhao, Z.M. Application of image method in calculating tunneling-induced soil displacement. J. Harbin Inst. Technol. 2005, 27, 801-803.

24. Zhao, Y.B.; Zhang, Z.M. Additional stress of surrounding soil caused by propelling of shield tunneling. Chin. J. Geotech. Eng. 2010, 32, 1386-1391.

25. Ni, P.P.; Mangalathu, S. Research articleFull text access Fragility analysis of gray iron pipelines subjected to tunneling induced ground settlement. Tunn. Undergr. Space Technol. 2018, 76, 133-144. [CrossRef]

26. Ni, P.; Mangalathu, S.; Yi, Y. Fragility analysis of continuous pipelines subject to transverse permanent ground deformation. Soils Found. 2018. [CrossRef]

27. Sun, T.L.; Zhang, Q.H.; Wei, L.W.; Wu, M.H.; Zhang, D.Y. Analysis of additional stresses of soil disturbance induced by propulsion of double-O-tube shield. Rock Soil Mech. 2008, 29, 2246-2251. (In Chinese)

28. Qi, J.J.; Xu, R.Q.; Wei, G.; Wang, T. Analysis of superimposed stress of surrounding soil due to shield tunneling. Rock Soil Mech. 2008, 29, 529-534.

29. Peng, C. Additional Stress and Settlement of the Soil Surface Research Caused by Shield Construction of Subway Tunnel; Central South University: Changsha, China, 2014.

30. Wu, C.F.; Wei, C.; Qiao, F.F. Analysis of additional soil stress caused by shield construction under existing superstructure loads. Chin. J. Rock Mech. Eng. 2018, 37, 1708-1720.

31. Mindlin, R.D. Force at a point in the interior of a semi-infinite solid. Physics 1936, 7, 195-201. [CrossRef]

32. Han, J.Y.; Zhao, W.; Jia, P.J.; Guan, Y.P.; Chen, Y.; Jiang, B.F. Risk Analysis of the Opening of Shield-Tunnel Circumferential Joints Induced by Adjacent Deep Excavation. J. Perform. Constr. Facil. 2018, 32, 04017123. [CrossRef] 
33. Sagaseta, C. Analysis of undrained soil deformation due to ground loss. Géotechnique 1987, 37, $301-320$. [CrossRef]

34. Chen, A.; Zhang, X.H.; Bai, Y.; Huang, D.Z.; Huang, Y. Analysis of the supermposed stress of soil layer induced by quasi rectangle EPB shield tunneling. Chin. J. Rock Mech. Eng. 2017, 36, 1814-1819.

35. Wang, H.X. Effect of cutter head compressing the front soil and influence of head aperture ratio on contact pressure of EPB shield to the front soil. China Civ. Eng. J. 2009, 42, 113-118.

36. Li, Y.; Zhao, Z. A numerical study on the influence of anchorage failure for a deep excavation retained by anchored pile walls. Adv. Mech. Eng. 2018, 10, 1-17.

37. Khoiri, M.; Ou, C.Y. Evaluation of deformation parameter for deep excavation in sand through case histories. Comput. Geotech. 2013, 47,57-67. [CrossRef]

38. Jia, P.J.; Zhao, W.; Chen, Y.; Li, S.G.; Han, J.Y.; Dong, J.C. A Case Study on the Application of the Steel Tube Slab Structure in Construction of a Subway Station. Appl. Sci. 2018, 8, 1437. [CrossRef]

39. Ji, X.; Ni, P.P.; Barla, M.; Zhao, W.; Mei, G. Earth pressure on shield excavation face for pipe jacking considering arching effect. Tunn. Undergr. Space Technol. 2018, 72, 17-27. [CrossRef]

40. Yang, X.; Li, Y.S. Research of surface settlement for a single arch long-span subway station using the Pipe-roof Pre-construction Method. Tunn. Undergr. Space Technol. 2018, 72, 210-217. [CrossRef]

(C) 2019 by the authors. Licensee MDPI, Basel, Switzerland. This article is an open access article distributed under the terms and conditions of the Creative Commons Attribution (CC BY) license (http:/ / creativecommons.org/licenses/by/4.0/). 